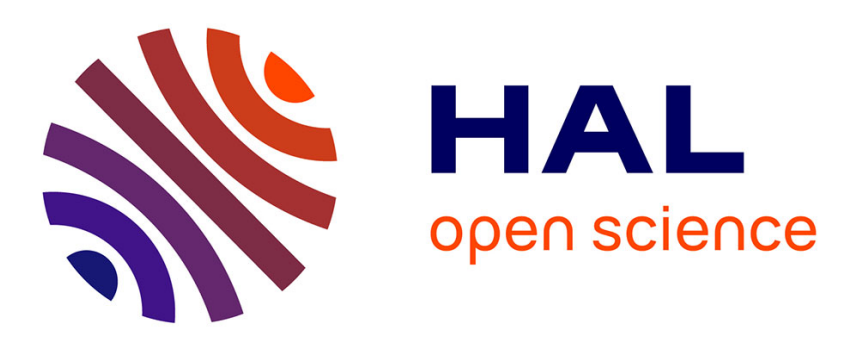

\title{
The use of distributed hydrological models for the Gard 2002 Flash-Flood event: Analysis of associated hydrological processes
}

Isabelle Braud, Hélène Roux, S. Anquetin, Marie-Madeleine Maubourguet, C. Manus, P. Viallet, Denis Dartus

\section{To cite this version:}

Isabelle Braud, Hélène Roux, S. Anquetin, Marie-Madeleine Maubourguet, C. Manus, et al.. The use of distributed hydrological models for the Gard 2002 Flash-Flood event: Analysis of associated hydrological processes. Journal of Hydrology, 2010, 394 (1-2), p. 162 - 181. 10.1016/j.jhydrol.2010.03.033 . hal-00546711

\section{HAL Id: hal-00546711 \\ https://hal.science/hal-00546711}

Submitted on 14 Dec 2010

HAL is a multi-disciplinary open access archive for the deposit and dissemination of scientific research documents, whether they are published or not. The documents may come from teaching and research institutions in France or abroad, or from public or private research centers.
L'archive ouverte pluridisciplinaire $\mathbf{H A L}$, est destinée au dépôt et à la diffusion de documents scientifiques de niveau recherche, publiés ou non, émanant des établissements d'enseignement et de recherche français ou étrangers, des laboratoires publics ou privés. 
Author-produced version of the article published in Journal of Hydrology, vol. 394, p. 162-181. The original publication is available at http://www.sciencedirect.com doi : 10.1016/j.jhydrol.2010.03.033

The use of distributed hydrological models for the Gard 2002 Flash-Flood event.

\section{Analysis of associated hydrological processes}

Isabelle Braud (1), Hélène Roux (2,3), Sandrine Anquetin (4), Marie-Madeleine Maubourguet $(2,3)$, Claire Manus (1,4), Pierre Viallet (5), Denis Dartus $(2,3)$

(1)

(1) Cemagref, UR HHLY, CP 220, 3bis Quai Chauveau, 69336 Lyon Cedex 9, France

(2) Université de Toulouse ; INPT, UPS ; IMFT (Institut de Mécanique des Fluides de Toulouse) ; F-31400 Toulouse, France

(3) CNRS ; IMFT ; F-31400 Toulouse, France

(4) Laboratoire d'étude des Transferts en Hydrologie et Environnement, Université de Grenoble (CNRS, UJF, IRD, INPG) (France)

(5) HYDROWIDE, 1025 Rue de la Piscine, Domaine universitaire, 38400 St-Martin d'Hères

This is the author's version of a work accepted for publication by Elsevier. Changes resulting from the publishing process, including peer review, editing, corrections, structural formatting and other quality control mechanisms, may not be reflected in this document. Changes may have been made to this work since it was submitted for publication. A definitive version was subsequently published as

Braud, I., Roux, H., Anquetin, S., Maubourguet, M.M., Manus, C., Viallet, P., Dartus D., 2010: The use of distributed hydrological models for the Gard 2002 Flash-Flood event. Analysis of associated hydrological processes, Journal of Hydrology, Flash Floods special issue, 394, 162-181, DOI:10.1016/j.jhydrol.2010.03.033

\section{http://www.sciencedirect.com/science/journal/00221694}




\section{$1 \quad$ Abstract}

2 This paper presents a detailed analysis of the September 8-9 2002 flash flood event in the

3 Gard region (southern France) using two distributed hydrological models: CVN built within

4 the LIQUID $^{\circledR}$ hydrological platform and MARINE. The models differ in terms of spatial

5 discretization, infiltration and water redistribution representation, and river flow transfer.

6 MARINE can also account for sub-surface lateral flow. Both models are set up using the same 7 available information, namely a DEM and a pedology map. They are forced with high resolution radar rainfall data over a set of 18 sub-catchments ranging from 2.5 to $99 \mathrm{~km}^{2}$ and are run without calibration. To begin with, models simulations are assessed against post field estimates of the time of peak and the maximum peak discharge showing a fair agreement for both models. The results are then discussed in terms of flow dynamics, runoff coefficients and soil saturation dynamics. The contribution of the sub-surface lateral flow is also quantified using the MARINE model. This analysis highlights that rainfall remains the first controlling factor of flash flood dynamics. High rainfall peak intensities are very influential of the maximum peak discharge for both models, but especially for the CVN model which has a simplified overland flow transfer. The river bed roughness also influences the peak intensity and time. Soil spatial representation is shown to have a significant role on runoff coefficients and on the spatial variability of saturation dynamics. Simulated soil saturation is found to be strongly related with soil depth and initial storage deficit maps, due to a full saturation of most of the area at the end of the event. When activated, the signature of sub-surface lateral

21 flow is also visible in the spatial patterns of soil saturation with higher values concentrating along the river network. However, the data currently available do not allow the assessment of both patterns. The paper concludes with a set of recommendations for enhancing field observations in order to progress in process understanding and gather a larger set of data to improve the realism of distributed models. 
Author-produced version of the article published in Journal of Hydrology, vol. 394, p. 162-181. The original publication is available at http://www.sciencedirect.com doi : 10.1016/j.jhydrol.2010.03.033

1

2 Keywords: Flash floods, distributed modelling, soil variability, hydrological processes,

3 saturation excess, infiltration excess, model inter-comparison

4

5

6 


\section{Introduction}

Flash floods represent the most destructive natural hazard in the Mediterranean region, causing around one billion Euros worth of damage in France over the last two decades (Gaume et al., 2009). Flash floods are associated with extreme and rare rainfall events and usually occur in ungauged river basins. Amongst them, small-ungauged catchments are recognized as the most vulnerable to storm driven flash floods (Ruin et al., 2008).

In order to limit damage to the population, there are several currently accepted methods for predicting flash floods in ungauged river basins. The flash flood guidance (Georgakakos, 2006; Norbiato et al., 2008) and the discharge threshold exceedance approach (Reed et al., 2007; Younis et al., 2008) are built to give an early flash flood warning with suitable time to organize the civil protection. These operational methods are very efficient for warning, but must be complemented with field experiments and modelling studies to improve the understanding of the major hydrological factors associated with the flood events. In order to progress in process understanding related to flash floods, large scale in situ experiments are scheduled in the context of the HyMeX program (www.hymex.org). This project aims at improving our understanding and prediction of the Mediterranean Sea water balance. The latter can be highly impacted by extreme events which provide a sudden input of fresh water to the sea (Drobinski et al., 2008). One of the focuses of HyMeX is therefore extreme events and, in particular, flash floods over the whole Mediterranean region. The objective is to better understand these events and to improve the predictive capability of hydro-meteorological models in simulating and anticipating them. The quantification of global change impact on the frequency and magnitude of these extreme events will also be analyzed within HyMeX. To achieve these goals, the HyMeX program is planning to enhance the observation capabilities of the scientific community in the Mediterranean region in order to better document extreme rainfall events and flash floods during a ten-year period, with an enhanced period of four 
1 years and two special observation periods in the fall. This experimental framework offers a

2 good opportunity to enhance hydrological process observations and understanding. Progress

3 in hydrological modelling of these events are also expected. As all the catchments cannot be

4 surveyed, it is important to determine which type of observations are required and, where and

5 when these observations are needed.

6 Distributed hydrological models, representing physical mechanisms, are interesting tools for 7 hypothesis testing and field design (Loague et al., 2006). Sensitivity studies to process representation, spatial discretization, input data and parameters can be performed that allow

9 the quantification of the impact of various functioning hypotheses on the hydrological response (Pinol et al., 1997, Sangati et al., 2009). Vivoni et al. (2007), using the tRIBs distributed model (Ivanov et al., 2004), explored the complex interactions between the various runoff contributions (infiltration excess, saturation excess, perched return flow, groundwater exfiltration) and the rainfall and catchments characteristics (soil, land use, topography). They showed how various responses can be observed at the outlet according to spatial and temporal variability of these factors and that threshold effects can be observed. Using the same model, Noto et al. (2008) focused on the impact of initial moisture (specified using a variable initial groundwater level) on the catchment response; they highlighted the complexity of the hydrological response to rainfall and soil characteristics. These studies focused on synthetic rainfall events and the studied catchment was about $800 \mathrm{~km}^{2}$. Extreme events were not considered in these studies and the analysis was performed for the whole catchment without 21 describing the internal variability.

22 The present paper deals with extreme events at the regional scale and aims at addressing small 23 ungauged catchments ranging from a few $\mathrm{km}^{2}$ to about $100 \mathrm{~km}^{2}$. In the context of the PUB 24 (Prediction of Ungauged Catchments) initiative, the questions addressed in the paper are the following: i) is it possible to set up physically-based distributed hydrological models at the 
1 regional scale using available data and information for flash flood simulation?; ii) are post-

2 flood data of maximum peak discharge useful to assess the relevance of the modelling?; iii)

3 are they relevant to discriminate between various model structures?; iv) are sensitivity studies,

4 based on distributed hydrological models outputs, useful to assess the limits of current

5 observations and highlight which information should be acquired in future field experiments,

6 in order to progress in the understanding and simulation of flash flood events for such

7 catchments. For this purpose, two distributed hydrological models with different model

8 structures are used. The study is conducted for the $8-9^{\text {th }}$ September 2002 event, which affected

9 the Gard region in south-east France. This event was exceptional, both in its extent (more than

$1020000 \mathrm{~km}^{2}$ affected) and duration, with more than $600 \mathrm{~mm}$ accumulated rainfall in $24 \mathrm{~h}$ in

11 some locations. For this event, radar rainfall and post flood field data of maximum peak

12 discharge are available.

13 The case study, rationale for model choice, model description and set up are presented first.

14 The methodology used for model evaluation based on maximum peak discharge and

15 sensitivity studies is also presented. The second part of the paper describes the model results

16 in terms of simulation of maximum peak discharge. This analysis is complemented by local

17 sensitivity studies and a discussion of model results in terms of hydrograph, runoff 18 coefficient, and soil saturation dynamics. After a discussion of the results, guidelines for

19 future experiments are proposed. These includes the processes, variables and parameters that 20 require further description and investigation. 


\section{$1 \quad$ Materials and methods}

\section{Case study and available data}

3 The case study is the September 8-9, 2002 event which affected the Gard region located in the

4 South-East of France (Figure 1). This event is the most important event ever recorded in this

5 region. It was responsible for 24 casualties and caused roughly 1.2 million euros worth of damage. This event was extensively described in Delrieu et al. (2005) and in Manus et al. (2009). Thus, we shall only present the data used in the present study. In terms of rainfall input, we used rainfall intensity data from the Bollène radar with a $1 \mathrm{x} 1 \mathrm{~km}^{2}$ grid resolution and a 5min time step, with the ST-AD3 processing protocol described by Delrieu et al. (2009). The spatial variability of soils is described using the Languedoc-Roussillon soil data base (later referred as BDSol-LR), provided by INRA (National Institute of Agronomic Research) from the French IGCS (Inventory, Management and Conservation of Soils) program. This database provides information (i.e. texture, horizon depth, etc..) on pedological landscape units called Soil Cartographic Units (SCUs). These units are established with a resolution of 1/250000 and they are geo-referenced. They are composed of Soil Typological Units (STUs), the vertical heterogeneity of which is described by stratified homogeneous layers of soil. The proportion of STUs is given within a particular SCU, but the precise location of STUs within this SCU is unkown. Each STU is described through tables providing both quantitative and qualitative information from which quantities such as percentage of sand, clay, silt, organic matter or soil depth can be derived. Pedo-transfer functions are used

21 to derive the hydraulic parameters of the various soil horizons (see details below). For model evaluation, we use data from an extensive post-flood investigation carried out during the months following the event. The methodology of Gaume and Bouvier (2004) was used during this field survey. The survey gathered a regional information about the flood, allowing the analysis of the hydrological behaviour of watersheds with an area of 2 to 300 
$1 \mathrm{~km}^{2}$. The procedure provides estimation of maximum discharges based on water level marks

2 and simple hydraulic hypotheses for the derivation of the flow velocity. The flood chronology

3 is documented based on witnesses interviews. A sub-set of data corresponding to the same 17

4 sub-catchments, already studied by Manus et al. (2009), is chosen. The area of these

5 catchments ranges from 2.5 to $50 \mathrm{~km}^{2}$ (Table 1). In addition, one $99 \mathrm{~km}^{2}$ gauged catchment,

6 the Saumane catchment, is also considered. Catchment locations are shown in Figure 1 and

7 their main characteristics are summarized in Table 1. The catchments located in the north-

8 western part of the domain have steep slopes, whereas the catchments located in the south-

9 eastern part of the domain are situated in flatter areas (Figure 1). Table 1 shows a large

10 variability in average soil depth and maximum storage capacity of these catchments. The

11 variables in Table 1 are derived from the BDsol-LR using the dominant STU in each SCU.

\section{Modelling hypotheses and model choice}

First of all, the choice of the model should be dictated by the objectives of the modelling exercise (e.g. Kamp and Burges, 2007). Concerning regional flash flood modelling, model requirements are presented in Borga et al. (2008) and Sangati et al. (2009). They underline that "the space-time excess rainfall distribution and drainage network structure provide the most important control on extreme flood response structure" (Sangati et al., 2009). Therefore, models used in regional flash flood studies should take into account high resolution rainfall and represent soil spatial variability. In order to conduct the study, two distributed hydrological models, able to cope with theses requirements, and differing in their structure are chosen. The first model is the CVN (Cévennes) model which is built within the LIQUID ${ }^{\circledR}$ hydrological modelling platform (Viallet et al., 2006; Branger et al., 2009 ${ }^{1}$ ). The second

\footnotetext{
${ }^{1}$ Branger, F., Braud, I., Debionne, S., Viallet, P., Dehotin, J., Hénine, H., Nédélec, Y., Anquetin, S., 2009. Towards multi-scale integrated hydrological models using the LIQUID framework. Overview of the concepts and first application examples, Environmental Modeling \& Software, in revision
} 
1 model is the MARINE model, dedicated to flash flood modelling (Maubourguet et al., 2007;

2 Bessière et al., 2008). The two models are representative of the variety of distributed

3 hydrological models used in flash flood event simulation (see references cited by Sangati et

4 al., 2009). In addition and in order to be useful for experimental design, the models must be

5 physically-based so that their inputs parameters and variables, and outputs variables can be

6 related to observable quantities. Kampf and Burges (2007) propose a synthesis and a

7 classification of distributed hydrological models, that highlights the main points which must

8 be considered when describing a model structure. Following this classification, the spatial

9 domain over which the model is applied, the space and time discretization, and the processes

10 which are considered, including surface/subsurface, overland, channel flows, and other

11 processes, as well as their coupling, must be described. These various points are reviewed

12 below for the two models, following the suggestion of Kampf and Burges (2007). Both models are applied at the catchment scale.

Models description

16

\section{MARINE}

The MARINE model is a spatially distributed rainfall-runoff model dedicated to extreme event simulation and developed on the basis of physical process representation. The model is structured as three physical modules (Figure 2a), which represent vertical transfer (infiltration and runoff generation for the soil component), lateral transfer and both the overland flow component and the flow through the drainage network. Interception and evapotranspiration are not represented since they are considered negligible during individual flood events.

The model output is a simulated hydrograph which is available at the catchment outlet but also at any point of the drainage network. It is also possible to follow the evolution of 
1 distributed variables such as soil moisture over all the catchment. A description of each model

2 component is detailed hereafter.

\section{Spatial discretization}

4 The spatial discretization of the catchment is performed using the Digital Elevation Model

5 grid resolution.

\section{$6 \quad$ Surface and subsurface flow}

7 Infiltration is described using the Green and Ampt (1911) model, which assumes one8 dimensional flow in vertically homogeneous soil columns.

9 The subsurface model is based on Darcy's law. Using the classical assumptions that (i) the slope of the water table in the saturated zone coincides with the local topographic slope, and

(ii) the local transmissivity is an exponential function of the local storage deficit (Original TOPMODEL assumption (Beven and Kirkby, 1979)), the flow per unit width $q$ is expressed as:

where $T_{0}$ is the local transmissivity of fully saturated soil $\left(\mathrm{m}^{2} \cdot \mathrm{s}^{-1}\right), \theta_{s}$ and $\theta$ are the saturated and local water contents $\left(\mathrm{m}^{3} \mathrm{~m}^{-3}\right), m$ is the transmissivity decay parameter (-) and $\beta$ is the local slope angle (-). Soil water can exfiltrate in two cases: (i) when the soil water content, $\theta$, exceeds saturated water content $\theta_{s}$; (ii) when the soil water reaches the drainage network. It is assumed that exfiltration into the drainage network occurs with a velocity calculated using equation (1). Both infiltration excess and saturation excess are therefore represented within

21 MARINE. In the present study, and in order to allow comparison with the CVN model, the 22 MARINE model is run without activation of the subsurface lateral flow component. In the sensitivity analysis, the impact of including subsurface flow in the modelling is discussed. 
1 The surface runoff is divided into two parts: the overland flow and the flow through the

2 drainage network. Both are simulated using the 1D kinematic wave approximation of the

3 Saint-Venant equations with the Manning friction law. When the drainage area becomes

4 greater than $1 \mathrm{~km}^{2}$, the overland flow is structured in a drainage network. Flow in this

5 drainage network takes into account a simplified network reach cross-section (Figure 2b).

6 This leads to a new transport equation in the drainage network. Characteristics of the network

7 reach are calculated using geomorphological considerations (Liu and Todini, 2002): network

8 reach width $W_{D i}$ and depth $H_{D i}$ are taken to increase as a function of the area drained by the $i^{\text {th }}$

9 cell, such that :

$$
\begin{aligned}
& W_{D i}=W_{D \max }+\left(\frac{W_{D \max }-W_{D \min }}{\sqrt{a_{t o t}}-\sqrt{a_{t h}}}\right)\left(\sqrt{a_{d i}}-\sqrt{a_{t o t}}\right) \\
& H_{D i}=H_{D \max }+\left(\frac{H_{D \max }-H_{D \min }}{\sqrt{a_{t o t}}-\sqrt{a_{t h}}}\right)\left(\sqrt{a_{d i}}-\sqrt{a_{t o t}}\right)
\end{aligned}
$$

11 where $W_{D \max }$ is the maximum width at the basin outlet, $W_{D \min }$ is the minimum width, corresponding to the threshold area $a_{t h}=1 \mathrm{~km}^{2}$, which is the minimum upstream drainage area required to initiate a channel, $a_{t o t}$ is the total area and $a_{d i}$ is the area drained by the $i^{\text {th }}$ cell.

MARINE is run with a fixed time step of $15 \mathrm{~s}$ for numerical stability reasons.

The CVN model is built within the LIQUID ${ }^{\circledR}$ modelling platform (Viallet et al., 2006). The system allows a customized model building by assembling process modules described with their own spatial discretization and numerical schemes. These modules can exchange fluxes both in space and time, and the interactions between the various modules are managed by a

21 time sequencer. Each model component is therefore run with an adaptative time step, consistent with its own dynamics. Using the LIQUID ${ }^{\circledR}$ modelling platform, model complexity can be increased step by step, allowing a better control and analysis of the impact of various 
1 model conceptualizations in terms of hydrological response. In this study, a first -simple-

2 version of the model is used. In particular, as in the MARINE model, interception and

3 evapotranspiration are neglected during the event.

\section{$4 \quad$ Spatial discretization}

5 The catchment discretization is based on the principles proposed by Dehotin and Braud 6 (2008) with several levels of discretization. The first level is composed of sub-catchments, 7 organised along the river network (Figure 3). The second level allows the introduction of some spatial heterogeneity within the sub-catchments, and leads to hydro-landscapes that are assumed homogeneous in terms of hydrological response. Rainfall input is also averaged at the scale of the hydro-landscapes. For flash-flood modelling, only soil heterogeneity as described by the pedology map is considered in the hydro-landscape delineation. The result is illustrated in Figure 3. The hydro-landscapes are the elementary units for the modelling of soil infiltration and vertical water redistribution. The hydro-landscapes are vertically discretized into soil horizons with different hydraulic properties.

\section{Surface and subsurface flow}

On each hydro-landscape, the Richards equation is solved using the Ross (2003) method as validated more extensively by Varado et al. (2006) and Crévoisier et al. (2009). The horizons are sub-divided into cells that are $1 \mathrm{~cm}$ thick for the stability of the numerical scheme. When the topsoil is saturated, ponding is generated. At the bottom of the hydro-landscapes, gravitational or zero flux boundary conditions can be imposed. Subsurface lateral transfer

21 between hydro-landscapes is not considered in this first version of the model.

\section{Overland and channel flow}

23 Transfer within the river network is performed using the 1D kinematic wave approximation of the St-Venant equation. The network is discretized into river reaches with one reach per subcatchment (Figure 3). The river section is assumed trapezoidal with geometrical parameters 
1 assigned according to the Strahler order. At this development stage of the model, the routing

2 scheme allowing the transfer of ponding generated on the hydro-landscapes to the river

3 reaches is very simple, as we are focusing on peak discharge and risk assessment,. The

4 ponding is quasi-instantaneously transferred to the closest river reach. The implications of

5 these simplifying hypotheses have been discussed by Manus et al. (2009) (see interactive

6 discussion) and are thus not repeated here.

\section{$7 \quad$ Model set up}

8 In order to be able to quantify differences and similarities in hydrological responses between

9 the two models, the same input data were used whenever possible. No calibration is 10 performed and both models are run using the a priori information and expert knowledge on 11 the various models derived from previous studies or model user expertise. These simulations 12 will be referred to as the reference simulations in the following of the paper.

\section{Spatial discretization}

14 Both models rely on Digital Elevation Model (DEM) data for river network and subcatchments delineation. The same $75 \mathrm{~m}$ resolution DEM, provided by IGN is used.

16 For the CVN model, the D8 algorithm (e.g. Tarboton, 1997) is used to define the drainage 17 direction map, the cumulated drainage area and the river network. A minimum drainage area of $0.1 \mathrm{~km}^{2}$ is used to distinguish between network and hillslope pixels. The Strahler order one sub-catchments are considered for the definition of the first level of discretization (Figure 3). This ensures that the hypothesis of instantaneous transfer of ponding to the closest river reach 21 is acceptable. For each river reach, the average slope is computed from the DEM slope information. Unfortunately, the DEM information is truncated to $1 \mathrm{~m}$ in height, which can sometimes lead to zero or very small slopes. This is corrected by assigning a minimum slope of $0.5 \mathrm{~m}$ (half the vertical DEM resolution) divided by the river reach length. 
1 This problem of DEM resolution is much more problematic for the MARINE model which

2 requires a continuity of flow at the scale of the DEM grid. To avoid problems, the DEM is

3 used with a $150 \mathrm{~m}$ resolution in MARINE. It is processed to identify connections between

4 cells, leading to the determination of the catchment extent and the flow pathways. DEM data

5 also allow the retrieval of hillslopes and cumulated drainage area, the drainage network and

6 the geometric characteristics of the network reaches. Drainage network extreme widths and

7 depths are derived from in situ measures. As in many rainfall-runoff models (Liu and Todini,

8 2002), drainage is only possible to the North, East, South or West for the four adjacent cells at

9 each edge in MARINE (D4 algorithm).

Figure $4 \mathrm{~b}$ shows the $30 \mathrm{~h}$ accumulated rainfall over the catchments. Rainfall is distributed at

11 the pixel scale within MARINE and at the hydro-landscape scale within CVN.

\section{Surface and subsurface flow}

13 For the specification of soil characteristics, the same pedology map, from the BDsol-LR is used by both models. As mentioned above, several Soil Typological Units (STUs) can be present within the Soil Cartographic Units (SCUs). In the present study, the dominant STU within each SCU was assumed representative of the whole SCU. A common map of soil depth and soil texture was built using this information.

Within MARINE, soils are assumed to be vertically homogeneous. Soil classes are assigned according to the Rawls and Brackensieck (1983) soil classes according to their texture. For each soil class, a set of parameters (saturated water content, soil suction for the Green and 21 Ampt model and saturated hydraulic conductivity) is assigned.

Within the CVN model, the vertical heterogeneity of the soil is considered and the soil hydraulic parameters of the Brooks and Corey (1964) retention and hydraulic conductivity curves are calculated as continuous functions of soil texture and soil porosity using the Rawls 
1 correction of soil saturated water content and hydraulic conductivity which takes into account

2 the stones content was proposed by Manus et al. (2009). This correction is applied to both the

3 CVN and MARINE parameters in the present study.

4 Figure 4a provides an illustration of the resulting variability in terms of maximum storage

5 capacity (calculated as the sum, over all the horizons, of soil saturated water content

6 multiplied by the horizon depth) amongst the studied catchments (Table 1). The range 7 amongst the catchments is very large from about $60 \mathrm{~mm}$ to $370 \mathrm{~mm}$.

8 The initial soil moisture is specified based on the SAFRAN-ISBA-MODCOU model with a

$98 \times 8 \mathrm{~km}^{2}$ resolution as provided by Météo-France (Habets et al., 2008). For MARINE, soil

10 parameters and initial soil moisture are distributed at the pixel scale. For the CVN model, soil

11 parameters are distributed at the hydro-landscape scale and initial soil moisture at the

12 catchment scale. Figures $4 \mathrm{c}$ and $4 \mathrm{~d}$ show the spatial variability of initial soil water storage

13 deficit (maximum storage capacity - initial soil water storage) for both the CVN and

14 MARINE models. Table 1 provides a summary of the maximum and initial water storage and

15 deficit per catchment. Initial soil water storage deficits are comparable between the models

16 with slightly lower values for MARINE than for CVN (-7\%). Figures $4 \mathrm{c}$ and $4 \mathrm{~d}$ show that

17 CVN exhibits a higher spatial variability of initial water storage deficit than MARINE due to

18 the use of continuous pedo-transfer functions. The CVN and MARINE model are run with a

19 zero flux bottom boundary condition.

\section{Overland and channel flow}

21 For the flow routing, a constant value of the Manning coefficient of 0.05 is used within the

22 CVN model (Manus et al., 2009).

23 For its overland flow routing, the MARINE model requires the specification of a roughness

24 coefficient. It is derived from a vegetation and land-use map (2000 Corine Land Cover 25 provided by the Service de l'Observation et des Statistiques (SOeS) of the French Ministry of 
1 Environment, www.ifen.fr). For the drainage network flow simulation within MARINE, two

2 Manning coefficients, corresponding to the main channel and the floodplain, must be 3 prescribed. They are taken from previous studies on the Gardons d'Anduze catchment with

4 values of 0.05 for the Manning roughness coefficient within the main channel and 0.125

5 within the floodplain (Bessière, 2008).

6 To conclude this section, the major similarities and differences between both model structures

7 are highlighted, based on the criteria proposed by Kampf and Burges (2007).

\section{Spatial discretization}

- The model discretizations are different. It is based on grid squares for MARINE and on homogeneous hydro-landscapes for CVN, with irregular polygonal shapes.

- Radar $1 \times 1 \mathrm{~km}^{2}$ and 5 min time step data are interpolated at the DTM grid scale within MARINE and at the hydro-landscape scale within CVN.

\section{Surface and subsurface fluxes}

- In terms of soil description, both models rely on the same soil depth and soil texture map, but the soil parameters are specified more coarsely in MARINE than in CVN (soil classes versus continuous pedo-transfer functions). Furthermore, the MARINE model assumes vertically homogeneous soils, whereas CVN accounts for vertical heterogeneity.

- Soil infiltration is described using the simplified Green and Ampt model in MARINE whereas the 1D Richards equation for saturated/unsaturated flow is used in CVN. CVN also explicitly accounts for water redistribution within the soil layers.

- Subsurface lateral flow is not considered in the intercomparison of both models

\section{Overland and channel flow}


- MARINE includes an hillslope overland flow module, based on the kinematic wave approximation of the de St-Venant equations, whereas CVN uses an empirical approach for overland flow routine

- In terms of river network, the MARINE discretization is finer and defined at the pixel scale, whereas homogeneous properties per river reach are assumed in CVN.

- The river section descriptions are also different and MARINE makes the distinction between the main channel and the floodplain, whereas only the main channel in considered in CVN. Both models use the kinematic wave approximation of the de StVenant equations for the flow routine module.

\section{Other processes and time discretization}

- Both models are run in this study as event-based models. A variable adaptative time step is used in CVN and a fixed time step is used in MARINE

- Both models neglect interception and evapotranspiration processes during the extreme rainfall event

- Both models use the finite volume approach for the numerical solution

The two models differ in terms of spatial discretization and have quite similar approaches in terms of soil infiltration representation, with a more refined representation within CVN. Both models differ in terms of water transfer, both within the hillslopes and river network, with a more refined scheme within MARINE.

\section{Model evaluation and sensitivity studies}

The simulations are conducted from $2002 / 09 / 08$ at $06 \mathrm{hUTC}$ to $2002 / 09 / 09$ at $12 \mathrm{hUTC}$, corresponding to the rainfall event duration.

Firstly, the performance of the models (reference simulations) is assessed at the regional scale using maximum peak discharge data collected during a post-flood field survey. As the models 
1 are not calibrated (reference simulation), a global sensitivity analysis to model parameters is 2 conducted in order to assess the uncertainty of the model estimates. Previous global 3 sensitivity studies, using the Monte-Carlo technique, have allowed determination of the most 4 sensitive parameters in MARINE for flash floods (Le, 2008). Their number is limited using 5 the method proposed by Refsgaard (1997) where, for distributed parameters, a spatial pattern 6 is fixed and the considered parameter is a multiplicative factor of the reference map. Three 7 sensitive parameters are identified by Le (2008): a multiplicative factor for the spatial pattern of soil thickness, a multiplicative factor for the spatial pattern of hydraulic conductivity and the roughness coefficient of the floodplain. When lateral subsurface flow is considered, an additional sensitive parameter is the multiplicative factor for the spatial pattern of saturated transmissivity. Based on these conclusions, a global sensitivity analysis is performed for both models for the September 2002 event using the latin hypercube method (see for instance van Griensven et al., 2006 for a review of sensitivity analysis methods) with 20 intervals for each parameter. Four parameters, namely a multiplicative factor for saturated hydraulic conductivity, a multiplicative factor for soil depth, the Manning coefficient (main channel for CVN and flood plain for MARINE, as previous sensitivity studies (Le, 2008) showed that the Manning coefficient for the main channel is not sensitive in MARINE), and the initial saturation are considered in the analysis. Based on expert knowledge in the region, the range and distributions presented in Table 2 are assigned to the various parameters. The target variables in this sensitivity analysis are the maximum specific peak discharge, time of peak, and the runoff coefficient of the various catchments. The impact of rainfall description has been studied in other papers (e.g. Carpenter and Georgakakos, 2004; Teztlaff and Uhlenbrook, 2005; Chancibault et al., 2006; Cole and Moore, 2008; Saulnier and Le Lay, 2009) and is not considered here where we focus more on the impact of the description of soil spatial variability and river flow. 
1 Secondly, as the results of both models are quite similar in terms of simulation of maximum

2 peak discharge and runoff coefficient, a comparative analysis of both model results is

3 performed in terms of discharge and soil saturation dynamics, in order to see if differences in

4 model behaviour can be identified. This analysis is complemented by local sensitivity studies

5 on some parameters, and studies of the impact of various model structural choices

6 (homogeneous versus distributed soils with CVN, inclusion of subsurface flow in MARINE).

\section{Results}

\section{$8 \quad$ Model evaluation using post flood event data}

9 Figure 5a shows the comparison of simulated maximum peak discharge with the field 10 estimates (including their uncertainty). Results are summarized in Table 3 which also 11 provides information on the peak discharge time, as derived from witness interviews when available. Figure 5a shows that MARINE simulated values are in general lower than the field observations, whereas CVN simulations tend to be higher. For both models, the peak discharge is overestimated for catchment \#10 and \#18. Rainfall estimation was found very uncertain for catchment $\# 10$, with krigged rainfall gauges leading to a cumulative value of $161 \mathrm{~mm}$ whereas the radar value was $339 \mathrm{~mm}$. Catchment \#18 is discussed in more detail below, as an hydrograph is available. When catchments \#10 and \#18 are excluded, the root mean square error is $112 \mathrm{~m}^{3} \mathrm{~s}^{-1}$ for MARINE and $96 \mathrm{~m}^{3} \mathrm{~s}^{-1}$ for CVN and the correlation coefficient between simulated and field values is $R^{2}=0.95$ for CVN with a slope of 1.14 , and $R^{2}=0.92$ for MARINE with a slope of 0.94 . The performance of both models is thus

21 satisfactory with regards to maximum peak discharge uncertainty.

22 Figure $5 \mathrm{~b}$ shows the comparison between simulated and field estimates of maximum specific peak discharge. The catchments are ordered with increasing area. We can see that maximum specific peak discharge tends to decrease with catchment area. Both models follow this trend. 
1 MARINE (respectively CVN) estimates are within the range of uncertainty for 8 (respectively

2 9) catchments over 18 , which is satisfactory for such events. If catchments \#10 and \#18 are 3 excluded, the root mean square error is $6.4 \mathrm{~m}^{3} \mathrm{~s}^{-1} \mathrm{~km}^{2}$ for MARINE and $6.7 \mathrm{~m}^{3} \mathrm{~s}^{-1} \mathrm{~km}^{2}$ for

4 CVN. As for maximum peak discharge, CVN tends to overestimate maximum specific 5 discharge, whereas MARINE tends to underestimate it.

6 For catchment \#18, a measured hydrograph is available, but the uncertainty in the measured 7 peak is large (Table 3). The comparison of the simulated and observed hydrographs is 8 provided in Figure $8 \mathrm{f}$. The simulated hydrographs are very similar for both models. Both 9 models overestimate the runoff volume and peak, the overestimation being larger for CVN. For this catchment, located the farthest from the radar, there may be some uncertainty on the rainfall estimate. A deeper analysis of rainfall estimates shows a cumulative rainfall of 208 $\mathrm{mm}$ with the radar data used in this study, $207 \mathrm{~mm}$ with the krigged rain gauges and only 145 $\mathrm{mm}$ with the data issued from the radar operational treatment. The observed runoff is $85 \mathrm{~mm}$ and Table 1 shows that the maximum storage capacity of the catchment is only $68 \mathrm{~mm}$. Therefore, even if the catchment was completely dry, the rainfall should not exceed $85+68=$ $153 \mathrm{~mm}$ to be consistent with the observed runoff. If we take into account uncertainty in the observed runoff by applying a multiplicative factor equal to the ratio of the upper bound to the most probable peak discharge 1050/770 $=1.36$, the "observed" runoff estimation reaches 116 $\mathrm{mm}$. Thus, the runoff plus storage only reaches $116+68=184 \mathrm{~mm}$, which is still below the estimated radar rainfall that we use $(208 \mathrm{~mm})$. The alternative hypothesis is an underestimation of catchment maximum storage capacity from the pedology map or the nonimperviousness of the bedrock.

These hypotheses and the robustness of the model estimates are examined more in details below using the global sensitivity analysis. 


\section{Global sensitivity analysis for the simulation of peak discharge and runoff coefficient}

2 The results of the global sensitivity analysis in terms of maximum specific discharge and

3 runoff coefficient are summarized in Figure 6 for both models. Almost none of the parameter

4 set is able to simulate the observed values of maximum specific discharge for catchments \#10 and \#18. It gives more credence to the hypothesis of a problem with rainfall estimation. For catchment \#18, only two parameters sets, associated with multiplicative factors of 8.1 (resp. 2.1) for saturated hydraulic conductivity, and of 3.6 (resp. 9.4) for soil depth, associated with dry initial conditions ( 0.11 and 0.34 respectively) are able to provide Nash efficiency values larger than 0.7 for both models. The high values of these multiplicative factors also questioned the relevance of the information provided by the soil data base about soil depth and the pedo-transfer functions used for the estimation of soil hydraulic properties. Enhanced in situ measurements of these properties are therefore required.

Figure 6 confirms the tendency observed in Figure 5 of an overestimation of maximum peak discharge by CVN and an underestimation by MARINE. For both models, the uncertainty range of the maximum specific peak discharge is in general within the error bounds of the post field data. For the catchments which are poorly simulated by $\mathrm{CVN}(\# 3,7,8,10,15$ to 18$)$ or MARINE (\#1, 4, 5, 8, 10, 12, 16 to 18$)$, the parameter uncertainty bounds are generally outside the errors bounds of the observed values. In terms of peak discharge (not shown), the time amplitude is small (less than 20 min, except when there are several peaks). When there is a peak of high rainfall intensities (larger than $100 \mathrm{~mm} \mathrm{hr}^{-1}$ ), the time of the peak is very stable, showing that these high rainfall intensities are probably very influential on the peak discharge, especially for the CVN model. For the CVN model, spurious rainfall intensity peaks might be the reason for the general overestimation on the badly simulated catchments. These rainfall peaks are likely to generate infiltration excess runoff, which is instantaneously transferred to the river network. Within the MARINE model, overland flow can smooth the impact of these 
1 rainfall peaks. For $\mathrm{CVN}$, the reference simulation is in general very close to the median

2 (Figure 6a), whereas it is closer to the $25^{\text {th }}$ quartile for MARINE.

3 In terms of runoff coefficient, the similarity between both model response is large (Figure 6c

4 and d). The large values of the median runoff coefficient for both models must be highlighted.

5 The CVN 95\% interval for the runoff coefficient is in general closer to a runoff coefficient of

61 than MARINE. Only some simulations (in general associated with the largest multiplicative

7 factors for soil depth) lead to small values of the runoff coefficient. Figure $7 \mathrm{~b}$ to $\mathrm{d}$ show the

8 relationship between the runoff coefficient and the multiplicative factors for saturated

9 hydraulic conductivity, soil depth and with initial saturation for catchment \#15, which is

10 representative of the other catchments. Both models present similar patterns, although the

11 absolute values are different (see next section). This shows that, despite the differences in

12 terms of surface and subsurface representation, the signature of the difference in model structure is weak in terms of runoff coefficient patterns. For the September 2002 extreme event, with an exceptionally large rainfall amount, a generalized soil saturation is simulated for most of the parameter sets. Neither the maximum peak discharge, nor the runoff coefficient allow the identification of significant differences in responses corresponding to differences in model structures for the runoff production components.

Figure 7a illustrates the dependence of the simulated maximum peak discharge as a function of the Manning coefficient for catchment \#15, but the pattern is similar for the other catchments. For both models, when the Manning coefficient is increased (in log scale), an

21 linear decrease of the maximum peak discharge is simulated. The slope of the relationship is smaller for MARINE than for CVN, showing a lower sensitivity of MARINE to this parameter. This also reflects the fact that MARINE distinguish between the main channel and the floodplain. The reference simulation values are quite different between both models, reflecting different choices in the flow routing and parameter values. When compared to the 
1 observed maximum peak discharge (horizontal lines), a range of more plausible values can be

2 highlighted. But the results are different according to the catchments (not shown). The

3 determination of a regional value for the Manning coefficient, based only on the maximum

4 peak discharge appears difficult.

5 In conclusion, given the available information and the uncertainty, both models perform

6 satisfactorily for a wide range of catchment sizes and rainfall input amounts. The results of

7 the global sensitivity analysis show that differences in model structures are not reflected in

8 differences in runoff coefficients. They are partly reflected in differences in maximum

9 specific discharge, but this variable is not sufficient to assess the most suitable model

10 structure. In the remaining of the paper, we go a step further by comparing the model results

11 in terms of simulated process dynamics (discharge and soil saturation) in order to see if

12 information on other variables could help determining which model structure better represents

13 actual processes. The reference simulation is used for this purpose.

14 Nevertheless, we would like to stress the value of post flood field data of maximum peak

15 discharge, as they are the only data available to assess model performance at the regional 16 scale and for catchment areas less than $100 \mathrm{~km}^{2}$. In Bonnifait et al. (2009), their Figure 6

17 shows that in the studied region, gauged catchments are only available for areas larger than

$18100 \mathrm{~km}^{2}$. Observed hydrographs are of course valuable to verify the simulated flow dynamics

19 for extreme events. However, discharge estimation remains very uncertain for extreme events 20 as stage-discharge relationships are often extrapolated far beyond the maximum gauged value 21 ,and only a few locations are gauged.

24 Figure 8 provides the simulated hydrographs by both models for some selected catchments.

25 The horizontal bars show the post flood field estimates of peak discharge and their 
1 uncertainty. When available, the times of the peak as stated by witnesses are shown as crosses. Table 3 shows the comparison between simulated and field estimates of peak discharge and time of peak for both models. Figure 8 shows that the shape of the simulated discharge is highly related to the rainfall dynamics with peaks in general associated with high rainfall intensities. The CVN model tends to be more reactive to rainfall than the MARINE model and shows more pronounced peaks than MARINE, with sometimes a large overestimation (\#3, \#7, \#8, \#16). It should be noted that MARINE also overestimates the peaks for these catchments (except \#3). Differences in model responses increase with increasing size of the catchment (Figure 8) with less pronounced peaks with MARINE than with CVN as long as the catchment area increases. The differences in the transfer modules lead to a larger smoothing of the hydrological response in MARINE than in CVN when the catchment size increases. These differences can be partly related to the transfer module and the difference in the Manning coefficient as shown in Figure 9 and Table 4, and confirmed by the global sensitivity analysis (Figure 7a). When the Manning coefficient is increased from 0.05 to $0.125 \mathrm{~m}^{-1 / 3} \mathrm{~s}^{-1}$, the peak discharge decrease by $16-36 \%$ in CVN and by $7-30 \%$ in MARINE. The time of peak is delayed by $10-30 \mathrm{~min}$ in CVN and by $20-30 \mathrm{~min}$ in MARINE. The case of \#17 is particular: two peaks are simulated and the change in roughness produces a change of the maximum peak in MARINE which leads to an $11 \mathrm{~h} 30$ hour difference. Figure 9 and Table 4 show that, in general, peaks occur in MARINE before they do in CVN when both models use the same roughness. This is certainly a consequence of the differences in 21 flow routing representations (as both models behave similarly in terms of runoff generation). 22 Figure 9 also shows that with identical roughness coefficients, the response of MARINE remains smoother than that of CVN. In particular, the decrease in peak discharge is less pronounced in MARINE which may be a consequence of the accounting of hillslope transfer within MARINE. 
1 When information about the peak hour is available, model estimates agree fairly well with the

2 values provided by the witnesses (or observation for Saumane), with a difference of less than

330 min for \#1 (second peak), \#6, \#9, \#17 and \#18. Differences in peak time estimates can

4 reach more than one hour for \#1 (first peak), \#3 and \#11. The dynamics of \#6 and \#9 are

5 particularly well represented by both models (Figure 6c). But these catchments have a very

6 shallow soil (Table 1) and are almost completely saturated on 09/08 at 12UTC, after only 6

7 hours of rainfall (see next section). Thus, the observed peaks are mainly explained by the

8 rainfall intensity peaks leading to saturation excess runoff. Both models well represent this

9 dynamic, showing that, for these small catchments (about $10 \mathrm{~km}^{2}$ ), water transfer was

10 satisfactorily represented.

11 As also shown by the global sensitivity analysis, for the different catchments, the simulated 12 peak hours by both models are quite similar although the transfer modules are different. However, the amplitude of the peaks is much higher in CVN than in MARINE. Generally, the sensitivity of MARINE to the Manning roughness coefficient is smaller than that of CVN. This is likely because of channel flow modelling which accounts for drainage network within 16 floodplains. More detailed information about the river bed, such as its geometry and 17 roughness would help improve the transfer modules of both models. The availability of distributed water height series (and preferably discharge series) at various scales could also be helpful in better characterizing flow dynamics.

21 Table 3 also provides the runoff coefficient, RC, simulated by both models. The average 22 difference between MARINE and CVN RC estimation is 0.04 in the range $[-0.01,0.15]$ and the root mean square difference is 0.07 . The difference between both models in terms of runoff coefficient is thus much higher than expected given the relative proximity in their 
1 which shows the relationships between the simulated $\mathrm{RC}$ and rainfall total amount, average

2 soil depth, initial storage deficit and initial saturation. On this graph, we have distinguished

3 between points with an acceptable or a bad simulation of maximum peak discharge. Figure 10

4 shows no significant correlation with all the variables for MARINE $\left(R^{2}<0.20\right)$, whereas a

5 significant relationship is found between CVN RC and average soil depth $\left(R^{2}=0.62, p<10^{-6}\right.$,

6 Figure 10b) and initial soil water deficit $\left(R^{2}=0.75, p<10^{-6}\right.$, Figure 10c). These relationships

7 remain valid when only the "good" simulations are taken into account. In CVN, the strong

8 relationship between runoff generation, soil depth and initial storage deficit is expected as the

9 generated ponding is highly related to soil depth and/or water storage deficit in the case of full saturation. As the ponding is directly routed to the river, all the ponding volume finally

11 reaches the outlet after being transferred within the river. The larger scatter for MARINE could be explained by the hillslope routing which allows some re-infiltration before the water reaches the river.

\section{Soil saturation dynamics}

Figure 11 maps the saturation state of each catchment at several times (from top to bottom: 8 September 2002 at 12hUTC, 9 September 2002 at 00hUTC, 9 September 2002 at $12 \mathrm{hUTC}$ ). The spatial distribution of the saturation states is quite similar for both models; however CVN simulation results in higher saturation, as can be seen in Figure 12. The final saturation is 0.96 for CVN while it is 0.90 for MARINE. This difference may be related to CVN's description of the vertical soil heterogeneity as explained in the model set up section. MARINE exhibits lower values of initial soil water storage deficit for deeper soils (Figure 4). However, the saturated hydraulic conductivity used in MARINE is generally lower than the one used by CVN with a ratio between both models ranging between 0.25 and about 9 (not shown). This may explain both the lower final saturation and the higher RC obtained with MARINE. Table 2 shows that MARINE runoff coefficients are lower than CVN RC only for 2 catchments. 
1 To illustrate the role of soil properties on the soil saturation dynamics, the mean saturation

2 state is plotted against different soil characteristics: soil classes (Figure 13a) and soil depths

3 (Figure 13b). Results show that soil spatial variability has a great impact on this dynamic.

4 Indeed, for both models, soils presenting high hydraulic conductivities $\left(13.2 \mathrm{~mm} \mathrm{~h}^{-1}\right.$ for class

$5 \mathrm{n}^{\circ} 4$ ) or low depths (ranging between $0 \mathrm{~m}$ and $0.2 \mathrm{~m}$ ) are rapidly saturated. The important

6 increase of saturation between September $8^{\text {th }} 2002$ at $18 \mathrm{hUTC}$ and September 9 at $00 \mathrm{hUTC}$

7 can be explained by the accumulated rainfall during these $6 \mathrm{~h}:$ locally more than $200 \mathrm{~mm}$ on catchments presenting class 4 soil texture (\#12, \#6), and locally more than $150 \mathrm{~mm}$ on catchments presenting low soil depths (\#9, \#11). For these soils, CVN and MARINE exhibit almost the same saturation dynamics: the vertical soil heterogeneity is indeed of little 11 importance in these cases. CVN presents higher saturation states than MARINE for soils with low hydraulic conductivities $\left(0.6 \mathrm{~mm} \mathrm{~h}^{-1}\right.$ for class $\left.\mathrm{n}^{\circ} 11\right)$ or large depths (ranging between 0.8 $\mathrm{m}$ and $1 \mathrm{~m}$ ) where soil can present high vertical heterogeneity. The important difference found for soil class $n^{\circ} 11$ may also be explained by the soil parameter specifications of each model: soil class $n^{\circ} 11$ covers an important range of soil textures (with a clay content ranging from 40 to $60 \%$ ) with different values of soil parameters in $\mathrm{CVN}$ as continuous pedo-transfer functions are used, while soil parameters are fixed for each soil class in MARINE. Indeed, it can be seen in Figure $14 \mathrm{~b}$ that the time evolution of the mean saturation states is highly related to the soil class and therefore to hydraulic conductivity in MARINE, whereas it is more related to soil depth (Figure 14a) in CVN. All these results emphasize the impact of the 21 spatial distribution of rainfall and soil properties on simulated soil saturation dynamics.

22 Figure 15 shows typical infiltration dynamics as simulated by the CVN models for different soil STUs. Figure 15 shows that for the shallowest soils, full saturation is reached on 09/08 at 12hUTC on US 430 (Figure 15a) and US 425 (Figure 15c), with the generation of infiltration excess runoff related to a low saturated hydraulic conductivity $\left(K_{s}=0.7 \mathrm{~mm} \mathrm{hr}^{-1}\right)$. Even if 
1 shallow, US 535 is saturated later on $09 / 09$ at $00 \mathrm{hUTC}$ (Figure $15 \mathrm{~b}$ ) due to a higher $K_{s}=14$

$2 \mathrm{~mm} \mathrm{hr}{ }^{-1}$. These three soils are fully saturated on $09 / 09$ at $00 \mathrm{hUTC}$, leading to saturation

3 excess runoff until the end of the event. With the no flux boundary condition, these profiles

4 do not change until the end of the simulation within the CVN model. For US 528, a moderate

5 value of $K_{s}=4 \mathrm{~mm} \mathrm{hr}^{-1}$, and a deep soil lead to a topsoil saturation, and the generation of

6 infiltration excess runoff, on 09/09 at 00hUTC (Figure 15d), but infiltration can continue into

7 deeper layers until $09 / 09$ at $12 \mathrm{hUTC}$ when the soil is fully saturated, generating saturation 8 excess runoff. Finally US 529 has a low $K_{s}=0.7 \mathrm{~mm} \mathrm{hr}^{-1}$ and two horizons. The first horizon is saturated on 09/09 at 18hUTC, but infiltration continues into the second horizon (Figure 15e). Infiltration excess runoff is generated throughout the whole event, but at the end, the soil is not fully saturated and saturation excess runoff has not occurred in this soil. If US 529 is assumed vertically homogeneous (Figure 15f), the topsoil saturation occurs later than with the two horizons on $09 / 0906 \mathrm{hUTC}$, and the soil is not fully saturated at the end of the event.

Sensitivity tests exploring the impact of soil spatial variability on the CVN simulated response are presented in this section for three catchments: \#15, \#17 and \#18. Catchment \#15 and \#17 were chosen for this sensitivity study because they have a large variability of soils with different storage capacity (Figure 4a) and hydraulic conductivities.

20 Simulations are performed using the same initial saturation rate as those given in Table 1.

21 Additional simulations are performed by using the same initial water storage deficit. Results are shown in Figure 16a, $\mathrm{b}$ and $\mathrm{c}$ and Table 5. The impact on peak discharge is moderate $( \pm$ 7\% for $\# 15$ and $\# 17$ and $+13 \%$ for $\# 18$ ), but the impact on runoff is significant with a 24 variation of \pm 0.10 in the runoff coefficient. In general the changes in runoff are related to the changes in initial soil water deficit and the increase/decrease in runoff amounts is equal to the 
1 increase/decrease in initial storage deficit. When the same initial storage deficit is used for

2 initial conditions, runoffs are very similar, but there is an impact on peak discharge of $\pm 7 \%$.

3 When soils are assumed to be vertically homogeneous instead of taking into account the

4 various horizons, the impact is limited to variations in the runoff coefficient and peak

5 discharge of a few percent. As does the previous analysis of soil saturation dynamics, this

6 sensitivity study highlights the importance of the initial water storage deficit on the

7 hydrological response at the outlet. Note that the quantification of initial conditions using a

8 saturation degree can lead to large differences in initial water storage deficit and is thus not

9 recommended. However, quantifying the initial soil water deficit is much more demanding in

10 terms of landscape description as it requires an accurate documentation of soil depths and

11 porosity.

\section{Impact of including subsurface flow within MARINE}

In order to test the impact of subsurface lateral flow within the MARINE model, a simulation is performed with the same parameters as the reference simulation and activation of subsurface lateral flow at a uniform subsurface velocity of $2 \mathrm{~m} \cdot \mathrm{h}^{-1}$. This value is chosen as 50 times the averaged Green and Ampt hydraulic conductivity over the whole studied area. Results show little sensitivity of peak discharge and runoff coefficient to subsurface flow with a maximum difference of respectively $-1 \%$ and +0.03 for $\# 18$ catchment. No impact on peak time is observed. It seems that for such an extremely intense and short event, slow subsurface lateral flow is of little importance in simulating peak time and discharge: with a simulation 21 duration of $30 \mathrm{~h}$ and a subsurface velocity of $2 \mathrm{~m} \cdot \mathrm{h}^{-1}$, no significant contribution of subsurface flow to outlet hydrographs is simulated. This conclusion should however not be generalized to less intense events. Indeed, introduction of subsurface flow slightly modifies the recession

24 simulation $\left(6 \mathrm{~m}^{3} \mathrm{~s}^{-1}\right.$ difference, hardly visible in Figure 16d), which may be of importance for 25 longer events with several rainfall peaks for instance. Moreover, the inclusion of subsurface 
1 lateral flow has an important impact on distributed saturation dynamics. Indeed, Figure 17

2 maps the saturation state of catchment \#18 at the end of the simulation (September $9^{\text {th }} 2002$ at

3 12hUTC) with and without subsurface flow. It clearly shows the importance of the drainage

4 network in the evolution of the saturation state when subsurface flow is considered. This is

5 due to the exfiltration that can occur in the drainage network. Measures describing the spatial

6 distributions of saturation state would be valuable to chose which processes must be 7 accounted for in the model.

\section{Discussion}

9 In this study, two distributed hydrological models are set up at the regional scale using the

10 available information and expert knowledge, without specific calibration. They are run.for the

11 September 8-9 2002 event in the Gard on 18 sub-catchments ranging from 2.5 to $99 \mathrm{~km}^{2}$ where data of maximum peak discharge, and sometimes time of peak are available. Post flood estimates of maximum peak discharge and time of peak are used to evaluate the models at the regional scale. This kind of information is very valuable because it is the only information available for small catchments. Up to now few studies (e.g. Bonnifait et al., 2009; Saulnier and Le Lay, 2009) have targeted the regional scale in the study area. These studies were based on a calibrated Topmodel approach. Bonnifait et al. (2009) also used the post flood field data for model evaluation but the comparison was restricted to catchments larger than $50 \mathrm{~km}^{2}$. The originality of our study is to tackle very small catchments, which were shown to be the most 20 vulnerable to flash floods (Ruin et al., 2008).

21 The comparison between field estimates and simulated peak discharge shows a reasonable agreement for half of the catchments for both models. The global sensitivity analysis on three soil parameters and the Manning coefficient shows that the results of the reference simulation in terms of maximum specific peak discharge are close to the median of the parameter set for $25 \mathrm{CVN}$ and to the $25^{\text {th }}$ quartile for MARINE. The uncertainty range of CVN are generally larger 
1 than that of MARINE. Further analysis shows that CVN is more sensitive to the Manning 2 roughness coefficient of the river bed than MARINE (for which it is the floodplain roughness coefficient) with a decrease of peak discharge when the Manning roughness coefficient is increased. Peak discharge could be used to reduce the range of plausible Manning roughness coefficients but, for the studied event, it seems difficult to find a unique value suitable for all the catchments. For some catchments, the sensitivity study highlights probable problems with the rainfall amount, as almost none of the parameter set is able to simulate the field peak discharge. The time of peak is found quite stable with regards to the parameters and most of the time, it is related to the time of high rainfall intensity peaks (larger than $100 \mathrm{~mm} \mathrm{hr}^{-1}$ ). The CVN model is more sensitive to these peak intensities than the MARINE model. In CVN such peak rainfall intensities generate infiltration excess runoff which is directly transferred to the closest river reach, leading to large peak discharge. In MARINE, overland flow allows possible re-infiltration of this infiltration excess runoff, and a smoothing of the impact of those peaks. The corresponding peak discharge are therefore lower. Post flood estimates of maximum discharge are therefore useful for analysing the impact of various flow routine modules. However, they do not allow the evaluation of the simulated flow dynamics and the identification of the most relevant model response. For this purpose, regional values of water height (and possibly peak discharge) are required in order to base the analysis of the whole hydrograph response. Our analysis should also be complemented by a study of the impact of river geometry on the results.

In terms of runoff coefficient, post flood maximum discharge estimate do not provide a mean to assess the relevance of the simulated results nor to discriminate between the two model structures. The global and local sensitivity analysis highlight the large impact of soil depth, saturated hydraulic conductivity and initial soil moisture on the simulated response, especially 
1 in terms of runoff coefficient. The global sensitivity analysis also shows that several

2 combinations of these parameters can lead to similar responses in terms of peak discharge or

3 runoff coefficient. A better knowledge - at the regional scale- of soil depths, hydraulic

4 properties and initial conditions is therefore required in order to reduce uncertainty in these

5 parameters and in model results (Loague and VanderKwaak, 2004; Ebel and Loague, 2006).

6 For the extreme September 2002 event, very high runoff coefficient are simulated by both

7 models. Differences in model responses, related to the different model representation can be

8 highlighted but they are masked by the importance of the event.

In the present study, evapotranspiration and interception processes are neglected. This hypothesis is reasonable given the duration of the event (one to two days) and the high rainfall intensities during the event. Vegetation and land use is considered within MARINE for the specification of the Manning roughness coefficient for overland flow, but a previous sensitivity analysis showed that this parameter is not very influential (Le, 2008). On the other hand, vegetation and land use do have a significant impact on initial conditions. A more comprehensive version of the CVN model is under construction. It will be used to study the impact of soil moisture. A continuous model is considered and an evapotranspiration module is being added to the current version of the model with parameters depending on the land use and vegetation.

21 Several studies (e.g., Carpenter and Georgakakos, 2004; Teztlaff and Uhlenbrook, 2005; 22 Chancibault et al., 2006; Cole and Moore, 2008; Saulnier and Le Lay, 2009) highlight the importance of an accurate quantification of the rainfall spatio-temporal dynamics for an accurate simulation of the catchment's response. This point is not explicitly addressed in our 
1 intensity peaks on the modelled results. The highest sensitivity of the CVN model to those

2 rainfall peaks is certainly related to its very simple overland flow representation. This

3 component of the model can be improved in the future. For some catchments where problems

4 are encountered with both models, rainfall accuracy is questioned. Therefore, the study

5 confirms the need for further work on the improvement of high spatial and temporal rainfall

6 resolution, and on the appropriate location of rainfall with regards to catchments boundaries.

7 Although the September 2002 event is perhaps too extreme to fully illustrate this point - due to a generalized soil satuation- our study also highlights the importance of the representation of soil spatial variability, both in terms of soil depths, porosity and hydraulic properties. Although infiltration excess runoff is generated for all the catchments due to the high rainfall 11 intensities, the soil water storage deficit is found to be very important when it comes to the timing of the response. This is in particular related to the threshold effect of full saturation of the soils. As a consequence, information about the initial soil water deficit is more relevant for the characterization of the initial moisture conditions than is the saturation degree of the catchments, as provided by the SAFRAN-ISBA-MODCOU model. However, the former estimation requires more data than the latter, as soil depths and porosity must be known with good accuracy. When subsurface lateral flow is considered, its impact on such an extreme event is found to be negligible in terms of peak discharge and runoff volume. However this conclusion must not be generalised to less intense events.

The saturation dynamics analysed at the regional scale, provide interesting insight into hydrological processes. When subsurface flow is not activated, the soil saturation patterns are mostly related to soil depth (and rainfall), whereas, when subsurface flow is considered, a second pattern of organisation along the river network is observed. Such patterns are typical of models based on the Topmodel concepts (e.g. Quinn et al., 1998). Patterns of soil moisture have been reported for small catchments using in situ data (e.g. Western et al., 2004; Latron 
1 and Gallart, 2007), but a much larger coverage would be required to assess the relevance of

2 our simulated patterns and the methodology proposed by Beldring et al. (1999) could be used.

3 Remote sensing of soil moisture has proven useful in reducing model parameter uncertainty in

4 hydrological models (e.g. Franks et al., 1998) and has been shown to improve their

5 performance (e.g. Pauwels et al., 2001). However, remote sensing only provides retrieval of

6 topsoil moisture whereas an integrated value other the whole profiles would be required.

7 Works are conducted to retrieve integrated soil moisture over the root zone from the

8 combination of surface soil moisture and soil vegetation atmosphere transfer modelling (e.g.

9 Calvet and Noilhan, 2000; Montaldo et al., 2003; Albergel et al., 2008). The application of

10 such techniques on the studied region should be evaluated, because information about 11 integrated soil moisture content is required to assess which of our simulated patterns is the 12 most realistic.

13 The general methodology proposed in this paper is the following i) set up of distributed hydrological models at the regional scale using the available data and expert knowledge without specific calibration; ii) a regional evaluation using the available information such as 16 available hydrographs, post flood data of maximum peak discharge and time of peak; iii) sensitivity studies to input data, parameters and process representation in order to get insight into the most sensitive points and derive information about processes, data and parameters requiring further measurements and understanding. It is applied to the September 2002 extreme event where the required data is available. Some interesting conclusions, summarized

21 below are drawn from this study. However, the event is so extreme that a general saturation of 22 the catchment is simulated, and the impact of various modelling hypotheses cannot be fully examined. The study should be repeated with less extreme events (Merz and Plate, 1997) in order to get more contrasted responses between catchments and models. The methodology can also be applied to other regions, provided the required data are available. 


\section{Conclusions}

3 In the introduction, four questions are highlighted. The results presented in this paper provide

4 some interesting responses. The study shows that it is possible to set up, at the regional scale,

5 distributed hydrological models, relevant for flash flood simulation, using available data and expert knowledge. It is a step towards the "model of everywhere", advocated by Beven (2003). Provided high spatial and temporal resolution of rainfall is available, post flood field data of maximum peak discharges and time of peak are valuable for the regional evaluation of these models. However, they are not sufficient for a full assessment of the simulated hydrological response in terms of flow dynamics, runoff coefficient and soil saturation dynamics. Model sensitivity studies including input data, parameters and process representation are very valuable in order to highlight where additional data could be useful.

This point is further detailed below where an experimental set up, suitable for improved understanding and modelling of flash floods is proposed in the context of the future HyMeX program. This experimental set up is based on nested instrumented catchments at various scales: i) densely instrumented small catchments of $1-10 \mathrm{~km}^{2}$, where process studies can be conducted; ii) larger instrumented catchments (of about $100-500 \mathrm{~km}^{2}$ ) where the change of scale problem can be tackled and, iii) regional catchments (of about 1000-10000 $\mathrm{km}^{2}$ ), where operational data are collected. Such a strategy is already implemented in African within the 21 AMMA project (Lebel et al., 2009), or in the UK in the framework of the Catchment Hydrology And Sustainable Management program (O’Connell et al., 2007). For flash floods studies, the following recommendations can be made:

- The information provided by post event field experiments about maximum peak discharge and time of peak is definitively recognised as very valuable, especially for small 
catchments. But the availability of enhanced networks of discharge series and/or water levels would increase our capability to specify hydrological models parameters and improve the process representations, through a better knowledge of the flow dynamics. The set up of LS-PIV (Large Scale Particle Image Velocimetry) networks (Muste et al., 2005; Le Coz et al., 2009²) and/or water level measurement networks (Sarrazin et al., 2009) which increase the density of this information in nested catchments is therefore encouraged.

- The spatial variability of soil depth and soil porosity, as well as hydraulic properties is found to be influential on the hydrological response and more specifically on the soil saturation patterns and dynamics. Up to now, this variability has been described through potentially altered substratum. The description of soil properties such as soil depth, porosity and hydraulic conductivity should thus be enhanced at the regional scale.

- Finally this study proposes different patterns of soil saturation dynamics according to different model hypotheses about the role of subsurface lateral flow. Regional mapping of soil saturation, over the whole profiles, would be required to determine which patterns are the most realistic as compared to field conditions. A combination of remote sensing data, in situ local measurements, and data assimilation could provide the necessary data.

\section{Acknowledgments}

21 The work presented in this paper was partly funded by the HYDRATE European Commission FP6 project under the $\mathrm{n}^{\circ} \mathrm{GOCE} 37024$. Olivier Vannier is thanked for processing the witness interviews used in the study. Radar data and part of the rainfall data were provided by Météo-

\footnotetext{
${ }^{2}$ Le Coz, J., Hauet, A., Dramais, G., Pierrefeu, G., 2010. Improvement of flash-flood discharge measurements using image-based velocimetry (LS-PIV), Journal of Hydrology, Flash Floods special issue, accepted.
} 
1 France. We acknowledge Electricite de France and the flood forecasting service SPC-GD for

2 the availability of the discharge data and the rest of rainfall data. The ST-AD3 radar data were

3 provided by Brice Boudevillain from LTHE Grenoble. Two anonymous reviewers and the

4 editors helped improving the quality of the paper. Stéphanie Moore carefully checked the

5 English language.

\section{References}

Albergel, c., Rüdiger, C., Pellarin, T., Calvet, J.C., Fritz, N., Froissard, F., Suquia, D., Petitba,

A., Piguet, B. and Martin, E., 2008. From near-surface to root-zone soil moisture using an exponential filter: an assessment of the method based on in-situ observations and model simulations. Hydrology and Earth System Sciences Discussion, 12, 1323-1337.

Beldring, S., Gottschalk, L., Seibert, J., Tallaksen, L.M., 1999. Distribution of soil moisture and groundwater levels at patch and catchment scales. Agricultural and Forest Meteorology, 98-99, 305-324.

Bessière, H., 2008. Assimilation de données variationnelle pour la modélisation hydrologique 16 distribuée des crues à cinétique rapide. Thèse de doctorat, Institut National Polytechnique de Toulouse, Toulouse, France, 350 pp.

Bessière, H., Roux, H., Dartus, D., 2008. Data assimilation for distributed flash flood modelling. Proceedings of the International Symposium on "Weather Radar and Hydrology", WRaH2008, March 10-12 2008, Grenoble, France, 4pp.

21 Beven, K., 2003. On environmental models of everywhere on the GRID. Hydrological Processes, 17, 171-174.

Beven, K., Kirkby, M. J., 1979. A physically-based variable contributing area model of basin hydrology, Hydrological Sciences Bulletin, 24, 43-69. 
1 Bonnifait, L., Delrieu, G., Le Lay, M., Boudevillain, B., Masson, A., Belleudy, P., Gaume, E.,

2 Saulnier, G.M., 2009. Distributed hydrologic and hydraulic modelling with radar rainfall

3 input: Reconstruction of the 8-9 September 2002 catastrophic flood event in the Gard

4 region, France, Advances in Water Resources, 37(7), 1077-1089.

5 Borga, M., Gaume, E., Creutin, J.D., Marchi, L., 2008. Surveying flash floods: gauging the 6 ungauged extremes. Hydrological Processes, 22, 3883-3885.

7 Brooks R.H., Corey, A.T., 1964. Hydraulic properties of porous media. Hydrology Papers, 8 Colorado State University, $24 \mathrm{pp}$.

9 Calvet, J.C., Noilhan, J., 2000. From near-surface to root zone soil moisture using year-round data. Journal of Hydrometeorology, 1(5), 393-411.

Carpenter, T.M. and Georgakakos, K.P., 2004. Impacts of parametric and radar rainfall uncertainty on the ensemble streamflow simulations of a distributed hydrologic model, J. of Hydrology, 2998, 202-221.

Chancibault, K., S. Anquetin, V. Ducrocq, and G. M. Saulnier, 2006. Hydrological evaluation of high-resolution precipitation forecasts of the Gard flash-flood event (8-9 September 2002). Q. J. R. Meteo. Soc., 132, 1091-1117.

Cole, S.J. and Moore, R.J., 2008. Hydrological modelling 1 using raingauge- and radar based estimators of areal rainfall, J. of Hydrology, 358, 159-181.

Crevoisier, D., Chanzy, A., Voltz, M., 2009. Evaluation of the Ross fast solution of Richards' equation in unfavourable conditions for standard finite element methods. Advances in 21 Water Resources, 32(6), 936-947.

22 Dehotin, J., Braud, I., 2008, Which spatial discretization for distributed hydrological models? Proposition of a methodology and illustration for medium to large-scale catchments, Hydrol. Earth Sys. Sci., 12, 769-796. 
1 Delrieu G., Ducrocq, V., Gaume, E., Nicol, J., Payrastre, O., Yates, O., Kirstetter, P.E.,

2 Andrieu, H., Ayral, P.-A., Bouvier, C., Creutin, J.-D., Livet, M., Anquetin, S., Lang, M.,

3 Neppel, L., Obled, C., Parent-du-Châtelet, J., Saulnier, G.-M., Walpersdorf, A., Wobrock,

W. 2005, The catastrophic flash-flood event of 8-9 September 2002 in the Gard region,

France: a first case study for the Cévennes-Vivarais Mediterranean Hydro-meteorological Observatory, J. Hydrometeorology, 6, 34-52.

Delrieu, G., Boudevillain, B., Nicol, J., Chapon, B., Kirstetter, P.E., Andrieu, H., Faure, D., 2009, Bollène 2002 experiment: radar rainfall estimation in the Cevennes-Vivarais region. Journal of Applied Meteorology and Climatology: DOI: 10.1175/2008JAMC1987.1.

Drobinski, P., Ducrocq, V., (Coordination), Béranger, K., Braud, I., Carlotti, F., Claud, C., Delrieu, G., Doerenbecher, A., Despiau, S., Dulac, F., Durrieu de Madron, X., Elbaz, F., Februrary 2008. 124 pp.

http://www.cnrm.meteo.fr/hymex/index.php?lang=english\&page=main_documents

Ebel, B.A., Loague, K., 2006. Physics-based hydrologic response simulation: seeing through the fog of equifinality. Hydrological Processes, 20, 2887-2900.

Franks, S.W., Gineste, P., Beven, K.J., Merot, P., 1998. On constraining the predictions of a distributed model: the incorporation of fuzzy estimates of saturated areas into the calibration process. Water Resources Research, 34(4), 787-797.

Gaume, E., Bain, V., Bernardara, P., Newinger, O., Barbuc, M., Bateman, A., Blaskovicová, L., Blöschl, G., Borga, M., Dumitrescu, A., Daliakopoulos, I., Garcia, J., Irimescu, A., Kohnova, S., Koutroulis, A., Marchi, L., Matreata, S., Medina, V., Preciso, E., Sempere- 
1 Torres, D., Stancalie, G., Szolgay, J., Tsanis, I., Velasco, D. and Viglione, A., 2009. A

2 compilation of data on European flash floods. Journal of Hydrology, 367(1-2), 70-78.

3 Gaume, E., Bouvier, E., 2004, Analyse hydro-pluviométrique des crues du Gard et du

4 Vidourle des 8 et 9 septembre 2002. La Houille Blanche, 6, 99-106. DOI : 10.1051/lhb:200406014

6 Georgakakos, K. P., 2006, Analytical results for operational flash flood guidance. J. Hydrol., soils. J. Agric. Sci., 4,1-24.

Habets, F., Boone, A., Champeaux, J.L., Etchevers, P., Franchistéguy, L., Leblois, E., 11 Ledoux, E., Le Moigne, P., Martin, E., Morel, S., Noilhan, J., Quintana-Segui, P., Rousset12 Regimbeau, F., Viennot, P., 2008. The SAFRAN-ISBA-MODCOU hydrometerological model applied over France. Journal of Geophysical Research, 113, D06113, doi:10.1029/2007JD008548.

Kampf, S.K., Burges, S.J., 2007. A framework for classifying and comparing distributed 16 hillslope and catchment hydrologic models. Water Resources Research, 43, W05423, doi: 10.1029/2006WR005370.

Ivanov, V.Y., Vivoni, E.R., Bras, R.L., Entekhabi, D., 2004. Catchment hydrologic response with a fully distributed triangulated irregular network model. Water Resources Research, 40(11), W11102, doi: 10.1029/2004WR003218.

21 Latron, J., Gallart, F., 2007. Seasonal dynamics of runoff-contributing areas in a small 22 mediterranean research catchment (Vallcebre, Eastern Pyrenees). Journal of Hydrology, 335(1-2), 194-206. 
1 Le, X.K., 2008. Variabilité des processus hydrologiques entrant dans le mécanisme de la

2 genèse des crues sur les bassins à cinétique rapide. Thèse de doctorat, Institut National

3 Polytechnique de Toulouse, Toulouse, France, $147 \mathrm{pp}$.

4 Lebel, T., Cappelaere, B., Galle, S., Hanan, N., Kergoat, L., Levis, S., Vieux, B., Descroix, 5 L., Gosset, M., Mougin, E., Peugeot, C., Seguis, L., 2009. AMMA-CATCH studies in the 6 Sahelian region of West-Africa: An overview. Journal of Hydrology, 375(1-2), 3-13.

7 Liu, Z., Todini, E., 2002. Towards a comprehensive physically-based rainfall-runoff model. Hydrology and Earth System Sciences, 6(5), 859-881.

Loague, K., Heppner, C., Mirus, B.B., Ebel, B.A., Carr, A.E., DBeVille, S.H., VanderKwaak, J.E., 2006. Physics-based hydrologic response simulation: foundation for hydroecology and hydrogeomorphology. Hydrological Processes, 20, 231-1237.

Loague, K., VanderKwaak, J.E., 2004. Physics-based hydrologic response simulation: platinium bridge, 1958 Edsal, or useful tool. Hydrological Processes, 18, 2949-2956.

Manus, C., Anquetin, S., Braud, I., Vandervaere, J.P., Viallet, P., Creutin, J.D. and Gaume, E., 2009. A modelling approach to assess the hydrological response of small Mediterranean catchments to the variability of soil characteristics in a context of extreme events, Hydrology and Earth System Sciences, 13, 79-97.

Merz, B., Plate, E.J., 1997. An analysis of the effects of spatial variability of soil and soil moisture on runoff. Water Resources Research, 33(12), 2909-2922.

Montaldo, N., Albertson, J.D., 2003. Multi-scale assimilation of surface soil moisture data for robust root zone moisture predictions. Advances in Water Resources, 26, 33-44.

Marchandise, A., 2007. Modélisation hydrologique distribuée sur le Gardon d'Anduze; étude comparative de différentes modèles pluie-débit, extrapolation de la normale à l'extrême et tests d'hypothèses sur les processus hydrologiques, Université de Montepellier II, Montpellier, 234 pp. 
1 Maubourguet, M-M., Chorda, J., Dartus, D., George, J., 2007. MARINE : Prévision des crues

2 éclair sur le Gardon d'Anduze. $1^{\text {rst }}$ HyMeX workshop, 9-11 January 2007, Toulouse, France.

$3 \quad$ Short Abstracts B19, p.57

4 Muste, M., Schone, J., Creutin, J.D., 2005. Measurements of free-surface flow velocity using 5 controlled surface waves, Flow Measurement and instrumentation, 16(1), 47-55.

6 Norbiato, D., Borga, M., Esposti, S.D., Gaume, E. and Anquetin, S., 2008. Flash flood 7 warning based on rainfall thresholds and soil moisture conditions: An assessment for gauged and ungauged basins. Journal of Hydrology, 362, 274-290.

Noto, L.V., Ivanov, V.Y., Bras, R.L., Vivoni, E.R., 2008. Effects of initialization on response of a fully-distributed hydrologic model. Journal of Hydrology, 352(1-2), 107-125.

O'Connell, E., Ewen, J., O'Donnell, G., Quinn, P.F., 2007. Is there a link between agricultural land-use managemetn and flooding? Hydrology and Earth System Sciences, 11(1), 96-107. catchments, Prades, Catalonia. The use of distributed models as aids to hypothesis formulation. Hydrological Processes, 11, 1287-1306.

Pauwels, V.R.N., Hoeben, R., Verhoest, N.E.C., De Troch, F.P., 2001. The importance of the spatial patterns of remotely sensed soil moisture in the improvement of discharge predictions for small-scale basins through data assimilation. Journal of Hydrology, 251, 88102.

Quinn, P.F., Ostendorf, B., Beven, K., Tenhumen, J., 1998. Spatial and temporal predictions 21 of soil moisture patterns and evaporative losses using TOPMODEL and the GAS-FLUX model for an Alaskan catchment. Hydrology and Earth System Sciences, 2(1), 51-64.

Rawls, W.J., Brakensiek, D.L., 1983. A procedure to predict Green Ampt infiltration parameters, Adv. Infiltration, Am. Soc. Agric. Eng., 102-112 
1 Rawls W.J., Brakensiek, D.L., 1985, Prediction of soil water properties for hydrologic

2 modelling. Jones, E.B. and Ward, T.J. eds. Watershed management in the eighties:

3 proceedings of the American Society of Civil Engineers symposium, Denver, April 30-May 1,1985. ASCE, New York, 293-299.

Reed, S., Schaake, J., Zhang, Z, 2007, A distributed hydrologic model and threshold frequency-based method for flash flood forecasting at ungauged locations. Journal of Hydrology, Vol. 337, Issue 3-4, 402-420.

Refsgaard, J.C., 1997. Parameterisation, calibration and validation of distributed hydrological models. J. of Hydrology, 198, 69-97

Ross, P.J., 2003, Modeling soil water and solute transport - Fast, simplified numerical solutions. Agronomy Journal, 95, 1352-1361.

Ruin, I., Creutin, J.D., Anquetin, S., Lutoff, C., 2008. Human exposure to flash-floodsrelation between flood parameters and human vulnerability during a storm of September 2002 in Southern France. Journal of Hydrology, 361, 199-213.

Sangati, M., Borga, M., Rabuffeti, D., Bechini, R., 2009. Influence of rainfall and soil properties spatial aggregation on extreme flash flood response modelling: an evaluation based on the Sesia river basin, North Western Italy. Advances in Water Resources, 32, 1090-1106.

Sarrazin, B., Braud, I., Lagouy, M., Bailly, J.S., Puech, C., Ayroles, H., 2009. A distributed water level network in ephemeral river reaches to identify the hydrological responses of anthropogenic catchments, EGU General Assembly, 19-24 April 2009, Vienna, Austria, Geophysical Research Abstracts, Vol 11, EGU2009-6103

Saulnier, G.M., Le Lay, M., 2009. Sensitivity of flash-flood simulations on the volume, the intensity, and the localization of rainfall in the Cévennes-Vivarais region (France). Water Resources Research, 45, W10425, doi: 10.1029/2008WR0069056. 
1 Tarboton, D.G., 1997. A new method for the detemrination of flow directions and contributing areas in Grid Digital Elevation models. Water Resources Research, 33(2), 309319.

Tetzlaff, D. and Uhlenbrook, S., 2005. Significance of spatial variability in precipitation for process-oriented modelling: results from two nested catchments using radar and ground station data. Hydrol. Earth Sys. Sci., 9: 29-41.

van Griensven, A., Meixner, T., Grunwald, S., Bishop, T., Diluzio, M., Srinivasan, R., 2006. A global sensitivity analysis tool for the parameters of multi-variable catchment models. Journal of Hydrology, 324(1-4), 10-23.

Varado, N., Ross, P.J., Braud, I., Haverkamp, R., 2006, Assessment of an efficient numerical solution of the Richards' equation for bare soil. J of Hydrol., 323(1-4), 244-257.

Viallet, P., Debionne, S., Braud, I., Dehotin, J., Haverkamp, R., Saâdi, Z., Anquetin, S., Branger, F., Varado, N., 2006, Towards multi-scale integrated hydrological models using the LIQUID framework, 7th International Conference on Hydroinformatics 2006, 4-8 September, Nice, France, Vol I, pp. 542-549.

Vivoni, E.R., Entekhabi, D., Bras, R.L., Ivanov, V.Y., 2007. Controls on runoff generation and scale-dependence in a distributed hydrological model. Hydrology and Earth System Sciences, 11, 1683-1701.

Western, A.W., Zhou, S.L., Grayson, R.B., McMahon, T.A., Blöschl, G., Wilson, D.J., 2004. Spatial correlation of soil moisture in small catchments and its relationship to dominant spatial hydrological processes. Journal of Hydrology, 286(1-4), 113-134.

Younis, J., Anquetin, S., Thielen, J., 2008, The benefit of High-Resolution operational weather forecasts for flash-flood warning, Hydrology and Earth System Sciences 12, 10391051. 


\section{List of figures}

Figure 1. Location of the study area, location of the simulated catchments and slope map of the region. The catchment numbers are those of Table 1. Coordinates are in extended Lambert II (m)

Figure 2. Scheme of the MARINE model. a) MARINE model structure. b) Geometry of a network cross section within the MARINE model

Figure 3. Scheme of the CVN model. Step 1 derives the hydrographic network and subcatchments boundary from the DTM. The river network provides the geometry for the 1D flow routine module. Step 2 derives the hydro-landscapes, used as elementary modeling unit for the Richards equation infiltration module, from the overlay of the pedology map and subcatchments boundaries. The hydro-landscapes are sub-divided into layers to account for soil vertical heterogeneity and ponding is directly transferred to the closest river reach.

Figure 4. a) Maximum soil water storage capacity (mm) for the studied catchments. b) Total cumulated rainfall (mm) between 2002/09/08 06hUTC and 2002/09/09 12hUTC. c) Initial soil water deficit (mm) for the CVN model on 2002/09/08 06hUTC. d) Initial soil water deficit (mm) for the MARINE model on 2002/09/08 06hUTC.

Figure 5. a) Comparison of simulated ( $\bullet$ for CVN and $\boldsymbol{\Delta}$ for MARINE) and field estimation of maximum peak discharge in a log-scale. The vertical bars along the 1:1 lines correspond to the uncertainty in the estimated values. b) Comparison of simulated ( $\bullet$ for CVN and $\boldsymbol{\Delta}$ for MARINE) and field estimation ( $\square$ with the corresponding error bar) maximum specific peak discharge. The $\mathrm{x}$-axis provides the catchment numbers (see Table 1) and the catchments are ordered with increasing area.

Figure 6. Boxplot of the global sensitivity analysis results on maximum specific peak discharge (top) and runoff coefficient (bottom) for the CVN model (left) and MARINE model (right). The thick line in the boxplot represents the median, the limits of the box provide the 
$25^{\text {th }}$ and $75^{\text {th }}$ quartiles and the whiskers provide the $95 \%$ confidence interval. Crosses are the outliers. For maximum specific discharge, the black points with the thick vertical lines are the in situ field estimates with their uncertainty range (see Table 3) ), and the black squares are the results of the reference simulation.

Figure 7. Most significant results of the sensitivity analysis for catchment \#15 (grabieux). (a) Maximum specific discharge as a function of Manning roughness coefficient $\left(\mathrm{m}^{-1 / 3} \mathrm{~s}\right)$. The horizontal full line is the in situ field estimate with its uncertainty (dashed line). Runoff coefficient as function of the (b) multiplicative factor for saturated hydraulic conductivity; (c) soil depth; and (d) of initial soil moisture. CVN results appear as black squares and MARINE results as open triangles. The larger symbols correspond to the reference simulation.

Figure 8. Examples of simulated hydrographs by the MARINE and CVN models for catchments (a) \#1, (b) \#3, (c) \#9, (d) \#15, (e) \#17, (f) \#18. The horizontal full lines are the field estimated peak discharge and the horizontal dashed lines are the confidence intervals. Crosses are drawn at the time of peaks as retrieved from witness interviews. The observed hydrograph for catchment \#18 is shown with black squares on panel (f). Catchments are presented in the figure in increasing area order.

Figure 9. Sensitivity study to the specification of the Manning coefficient of the CVN model .(reference value: $n=0.05 \mathrm{~m}^{-1 / 3} \mathrm{~s}$, tested value: $n=0.125 \mathrm{~m}^{-1 / 3} \mathrm{~s}$ ) and of the floodplain Manning coefficient of the MARINE model (reference value: $n=0.125 \mathrm{~m}^{-1 / 3} \mathrm{~s}$; tested value: $n=0.05 \mathrm{~m}^{-1 / 3}$ s) for (a) \#10; (b) \#15; (c) \#17; (d) \#18.

Figure 10. Relationship between catchment simulated runoff coefficients and (a) total rainfall amount ; (b) average soil depth ; (c) initial soil water deficit (mm); (d) initial saturation ratio. The graphs distinguished catchments for which the simulation of maximum peak discharge is within the error bounds ("good") and out the error bounds ("bad"). 
Figure 11. Maps of the simulated soil saturation state by CVN (left) and MARINE (right) for three dates: 09/08 12hUTC (top), 09/09 00hUTC (middle) and 09/09 12hUTC (bottom).

Figure 12. Time evolution of the average saturation state other the whole studied area for both models.

Figure 13. Example of time evolution of the mean saturation state for different types of soils a) Rawls and Brakensiek 4 and 11 soil classes (4: loam; 11: clay); Soil depths ranging between 0-0.2 $\mathrm{m}$ and $0.8-1 \mathrm{~m}$ are distinguished.

Figure 14. Correlation of the saturation dynamics with soil properties at several times (square: 8 september at 12:00; triangle: 9 september at 00h; diamond: 9 september at 12h) a) Soil depths for CVN; b) Soil classes for MARINE (4: loam; 7: clay loam; 11: clay - Only soil classes present in more than 1000 cells of the grid have been taken into account).

Figure 15. Time evolution of the soil saturation profiles of six different soils on different catchments. (a) \#15 US 430; (b) \#15 US 535; (c) \#17 US 425; (d) \#15 US 528; (e) \#17 US 529; (f) \#17 US 529 vertically homogeneous. The symbols correspond to the various dates: (full line) 2002/09/08 06h00; (ם) 2002/09/08 12h00; ( $\mathbf{\Delta}$ ) 2002/09/08 18h00; (口) 2002/09/09 00h00; (ロ) 2002/09/09 12h00; (+) 2002/09/09 12h00.

Figure 16. (a) Sensitivity to the soil representation on \#15 for the CVN model; (b) Sensitivity to the soil representation on $\# 17$ for the CVN model (c) Sensitivity to the soil representation on \#18 for the CVN model; (d) Sensitivity of the MARINE model to inclusion of sub-surface flow on \#18

Figure 17. Spatial distribution of the saturation state of \#18 catchment on September 92002 at 12hUTC simulated with MARINE model a) without subsurface lateral flow b) with subsurface lateral flow at a uniform velocity of $2 \mathrm{~m} \cdot \mathrm{h}^{-1}$. 
Table 1. Characteristics summary of the studied catchments, ordered by increasing area.

\begin{tabular}{|c|c|c|c|c|c|c|c|c|}
\hline$\#$ & Catchment name & Area $\left(\mathrm{km}^{2}\right)$ & $\begin{array}{l}\text { Average soil } \\
\text { depth }(\mathrm{cm})\end{array}$ & $\begin{array}{l}\text { CVN } \\
\text { maximum } \\
\text { storage } \\
\text { capacity }(\mathrm{mm})\end{array}$ & $\begin{array}{l}\text { MARINE } \\
\text { maximum } \\
\text { storage } \\
\text { capacity }(\mathrm{mm})\end{array}$ & $\begin{array}{l}\text { Initial } \\
\text { saturation }(\%)\end{array}$ & $\begin{array}{l}\text { CVN } \\
\text { initial } \\
\text { storage } \\
\text { deficit } \\
(\mathrm{mm}) \\
\end{array}$ & $\begin{array}{l}\text { MARINE } \\
\text { initial storage } \\
\text { deficit }(\mathrm{mm})\end{array}$ \\
\hline 1 & alzon_sec 05 & 2.5 & 49 & 155 & 146 & 54 & 71 & 67 \\
\hline 2 & alzon_sec04 & 3.4 & 21 & 94 & 88 & 54 & 43 & 40 \\
\hline 3 & droude_sec04 & 4.0 & 84 & 374 & 352 & 55 & 169 & 158 \\
\hline 6 & ourne_sec03 & 10.2 & 25 & 104 & 98 & 58 & 43 & 41 \\
\hline 7 & braune_sec05 & 11.6 & 43 & 145 & 137 & 57 & 62 & 59 \\
\hline 8 & bourdic_sec02 & 12.0 & 45 & 145 & 97 & 62 & 43 & 41 \\
\hline 9 & ourne_sec02 & 12.0 & 26 & 103 & 137 & 58 & 55 & 52 \\
\hline 10 & braune_sec01 & 14.6 & 73 & 223 & 208 & 58 & 92 & 86 \\
\hline 11 & alzon_sec03 & 16.0 & 30 & 123 & 113 & 54 & 56 & 52 \\
\hline 12 & crieulon_sec01 & 19.0 & 96 & 397 & 366 & 68 & 128 & 117 \\
\hline 17 & courme_sec04 & 50.2 & 81 & 336 & 314 & 61 & 131 & 123 \\
\hline 18 & saumane & 99.0 & 19 & 68 & 53 & 46 & 36 & 29 \\
\hline
\end{tabular}


Author-produced version of the article published in Journal of Hydrology, vol. 394, p. 162-181.

Table 2: Distributions and range of the parameters used in the global sensitivity analysis

\begin{tabular}{llll}
\hline Parameter & Range & Type of distribution & Comment \\
\hline Multiplicative factor for saturated hydraulic & {$[0.01,100]$} & log-normal & Local in situ field measurements report high \\
conductivity & & & saturated hydraulic conductivity (Marchandise, \\
& & & Log-normal \\
Multiplicative factor for soil depth & {$[0.01,10]$} & Log-normal & From the literature \\
Manning coefficient (main channel for CVN, & {$[0.01,0.2]$} & & \\
floodplain for MARINE) & & uniform & \\
Initial soil saturation & {$[0,1]$} & & \\
\end{tabular}


Table 3. Estimated and simulated maximum peak discharge. Estimated and simulated time of peak. When two values are provided, it corresponds to two successive peaks. Simulated runoff coefficients (RC) for the MARINE and CVN models.

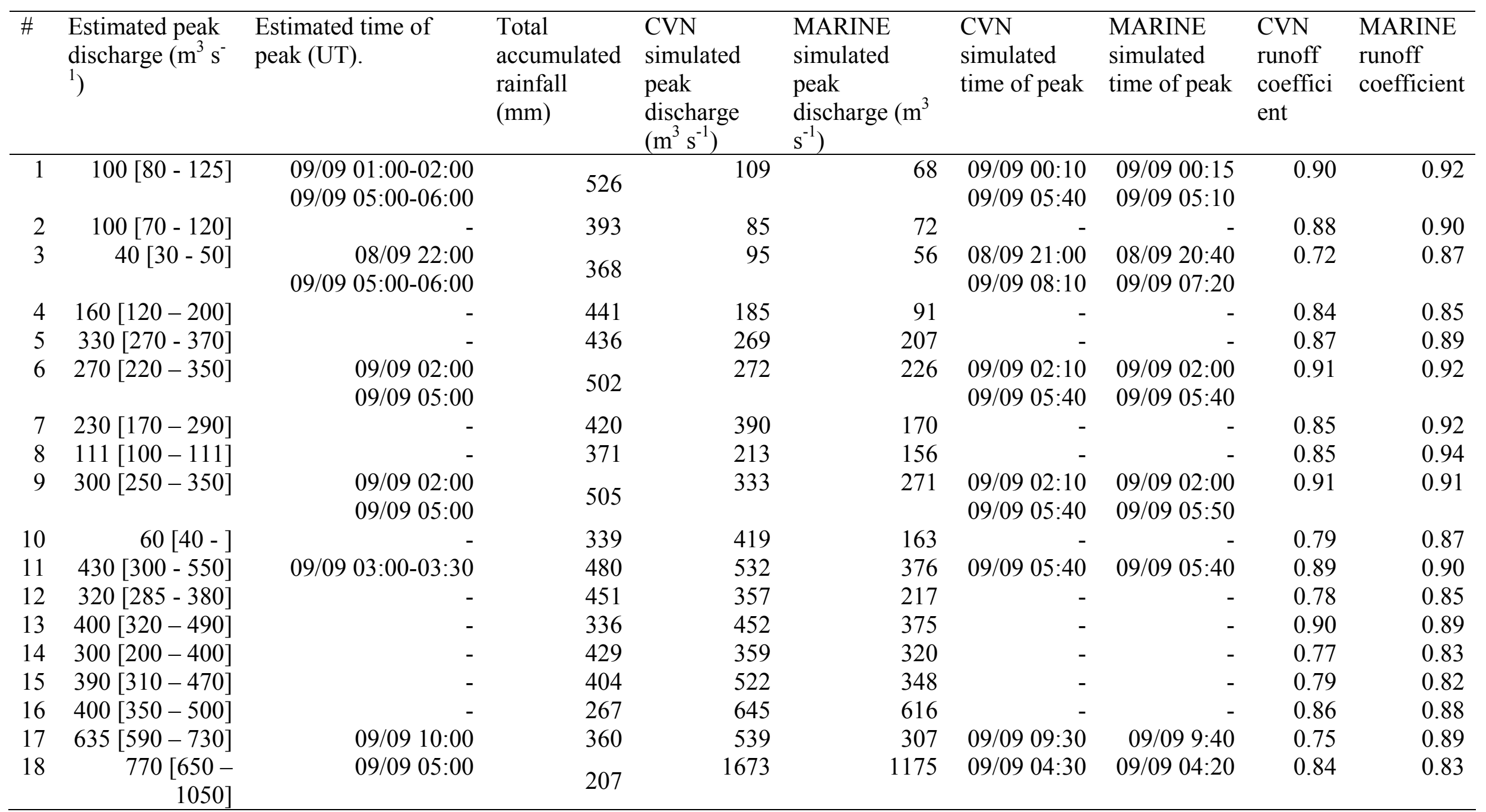


Table 4. Sensitivity study to the specification of the Manning coefficient of the CVN model .(reference value: $n=0.05 \mathrm{~m}^{-1 / 3} . \mathrm{s}$, tested value: $\left.n=0.125 \mathrm{~m}^{-1 / 3} . \mathrm{s} ;.\right)$ and of the floodplain Manning coefficient of the MARINE model (reference value: $n=0.125 \mathrm{~m}^{-1 / 3} . \mathrm{s} ;$ tested value: $n=0.05 \mathrm{~m}^{-}$ ${ }^{1 / 3}$.s.) for 4 catchments.

\begin{tabular}{|c|c|c|c|c|c|c|c|c|}
\hline$\#$ & $\begin{array}{l}\text { CVN peak } \\
\text { discharge } \\
\left(\mathrm{m}^{3} \mathrm{~s}^{-1}\right) \\
\end{array}$ & $\begin{array}{l}\text { CVN time of } \\
\text { peak (UTC) }\end{array}$ & $\begin{array}{l}\text { CVN peak } \\
\text { discharge }\left(\mathrm{m}^{3} \mathrm{~s}^{-}\right. \\
\left.{ }^{1}\right)\end{array}$ & $\begin{array}{l}\text { CVN time of } \\
\text { peak (UTC) }\end{array}$ & $\begin{array}{l}\text { MARINE peak } \\
\text { discharge } \\
\left(\mathrm{m}^{3} \mathrm{~s}^{-1}\right)\end{array}$ & $\begin{array}{l}\text { MARINE time } \\
\text { of peak (UTC) }\end{array}$ & $\begin{array}{l}\text { MARINE peak } \\
\text { discharge }\left(\mathrm{m}^{3} \mathrm{~s}^{-1}\right)\end{array}$ & $\begin{array}{l}\text { MARINE time } \\
\text { of peak (UTC) }\end{array}$ \\
\hline$n$ & 0.05 & & 0.125 & & 0.05 & & 0.125 & \\
\hline 15 & 516 & 09/09 05h50 & 375 & 09/09 05h50 & 435 & 09/09 05h40 & 348 & 09/09 06h10 \\
\hline 17 & 539 & 09/09 09h30 & 345 & 09/09 10h20 & 446 & 09/09 09h00 & 307 & $08 / 0921 \mathrm{~h} 30$ \\
\hline 18 & 1673 & 09/09 04h30 & 1392 & 09/09 05h00 & 1291 & 09/09 04h00 & 1175 & $09 / 0904 \mathrm{~h} 20$ \\
\hline
\end{tabular}


Table 5. Sensitivity studies using the CVN model. The reference simulations were performed with the distributed soils and a Manning roughness coefficient of 0.05 . US 528, 535, 607 belong to MARINE textural class 4 (loam); US 430 and 529 to class 7 (clay loam); and US 425 to class 11 (clay).

\begin{tabular}{|c|c|c|c|c|c|}
\hline Simulation & $\begin{array}{l}\text { Initial water } \\
\text { storage deficit } \\
\text { (mm) }\end{array}$ & $\begin{array}{l}\text { Maximum peak } \\
\text { discharge }\left(\mathrm{m}^{3} \mathrm{~s}^{-1}\right)\end{array}$ & $\begin{array}{l}\text { Time of peak (UT) } \\
\text { 2002/09/09 }\end{array}$ & Total runoff (mm) & Runoff coefficient \\
\hline \multicolumn{6}{|c|}{ Grabieux \#15 (rainfall $404 \mathrm{~mm}$ ) } \\
\hline Reference simulation & 80 & 522 & $05 \mathrm{~h} 40$ & 323 & 0.80 \\
\hline Uniform soil US 430 & 30 & 548 & $05 \mathrm{~h} 40$ & 372 & 0.92 \\
\hline Uniform soil US 528 & 134 & 486 & $05 \mathrm{~h} 40$ & 269 & 0.66 \\
\hline Uniform soil US 535 & 64 & 548 & $05 \mathrm{~h} 40$ & 338 & 0.84 \\
\hline Uniform soil US 528 & 80 & 548 & $05 \mathrm{~h} 40$ & 320 & 0.79 \\
\hline Uniform soil US 528 & 123 & 570 & $09 \mathrm{~h} 20$ & 232 & 0.64 \\
\hline Uniform soil US 529 & 172 & 514 & $09 \mathrm{~h} 30$ & 255 & 0.71 \\
\hline Uniform soil US 430 & 52 & 573 & $09 \mathrm{~h} 20$ & 299 & 0.83 \\
\hline Uniform soil US 529 & 131 & 514 & $09 \mathrm{~h} 30$ & 255 & 0.71 \\
\hline $\begin{array}{l}\text { Uniform soil US } 529 \text { vertically } \\
\text { homogeneous }\end{array}$ & 166 & 513 & 09h30 & 247 & 0.69 \\
\hline Vertically homogeneous soil & 38 & 1674 & $04 \mathrm{~h} 30$ & 170 & 0.82 \\
\hline
\end{tabular}




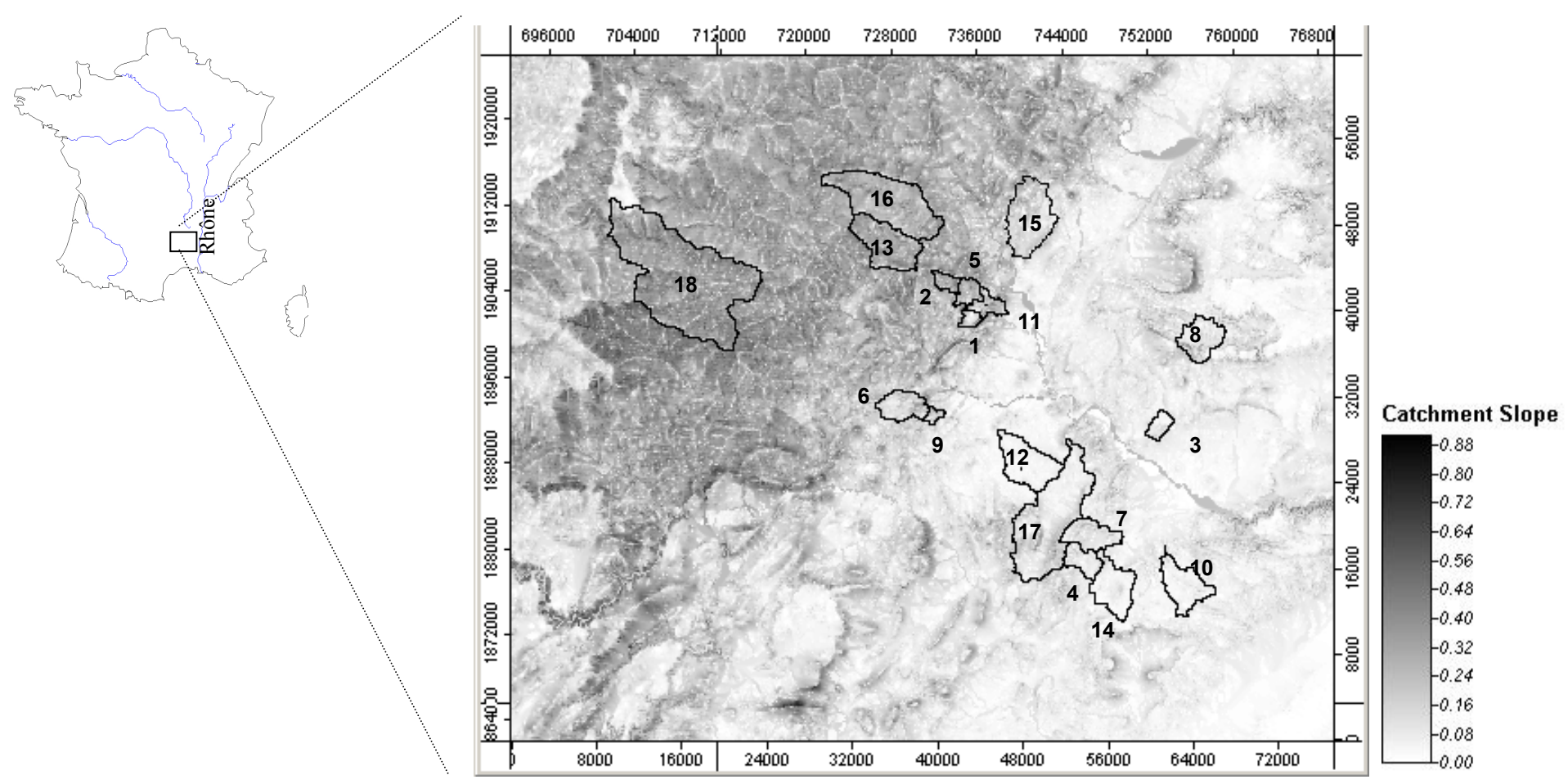

Figure 1. 
Author-produced version of the article published in Journal of Hydrology, vol. 394, p. 162-181.

a)

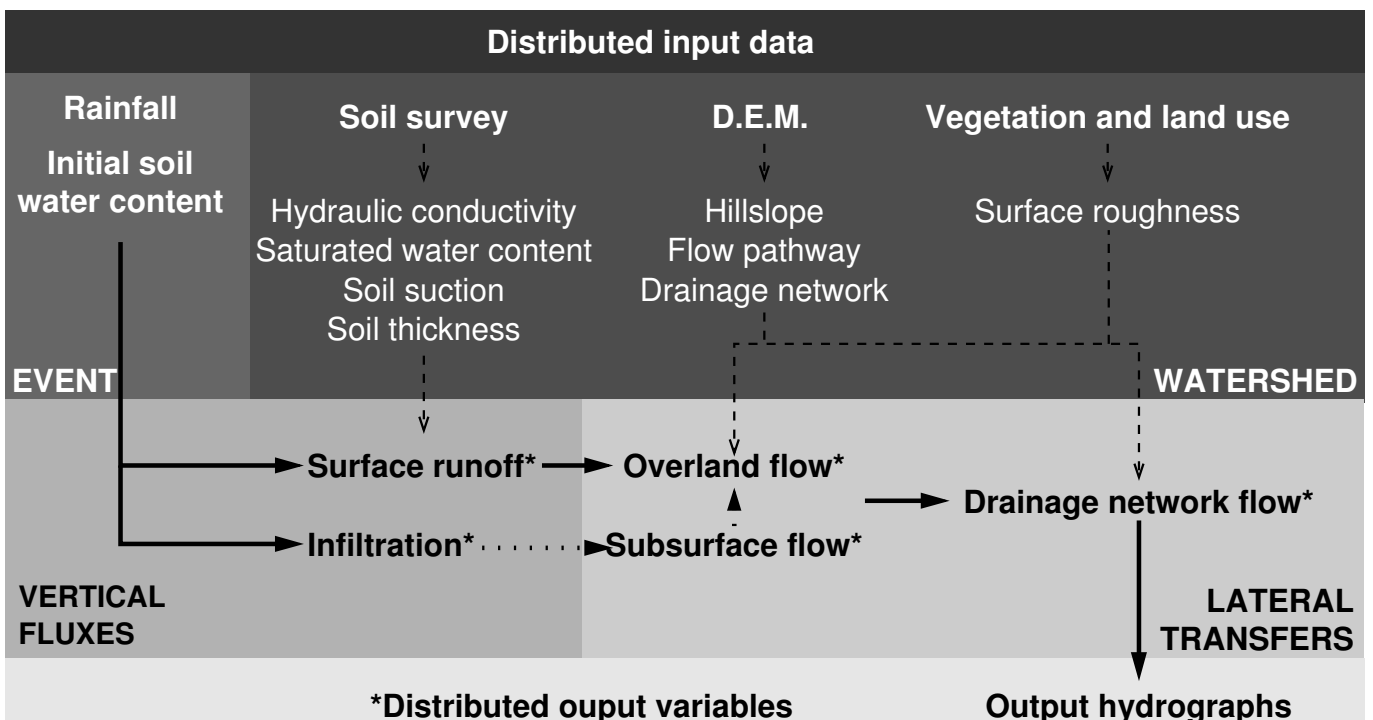

b)

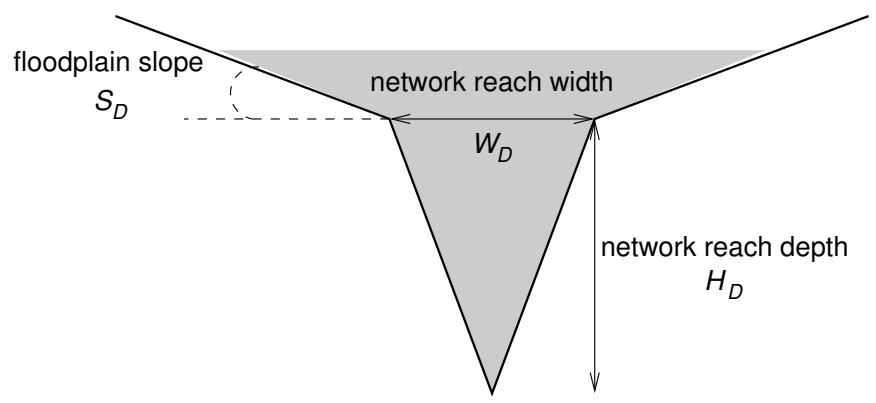

Figure 2 


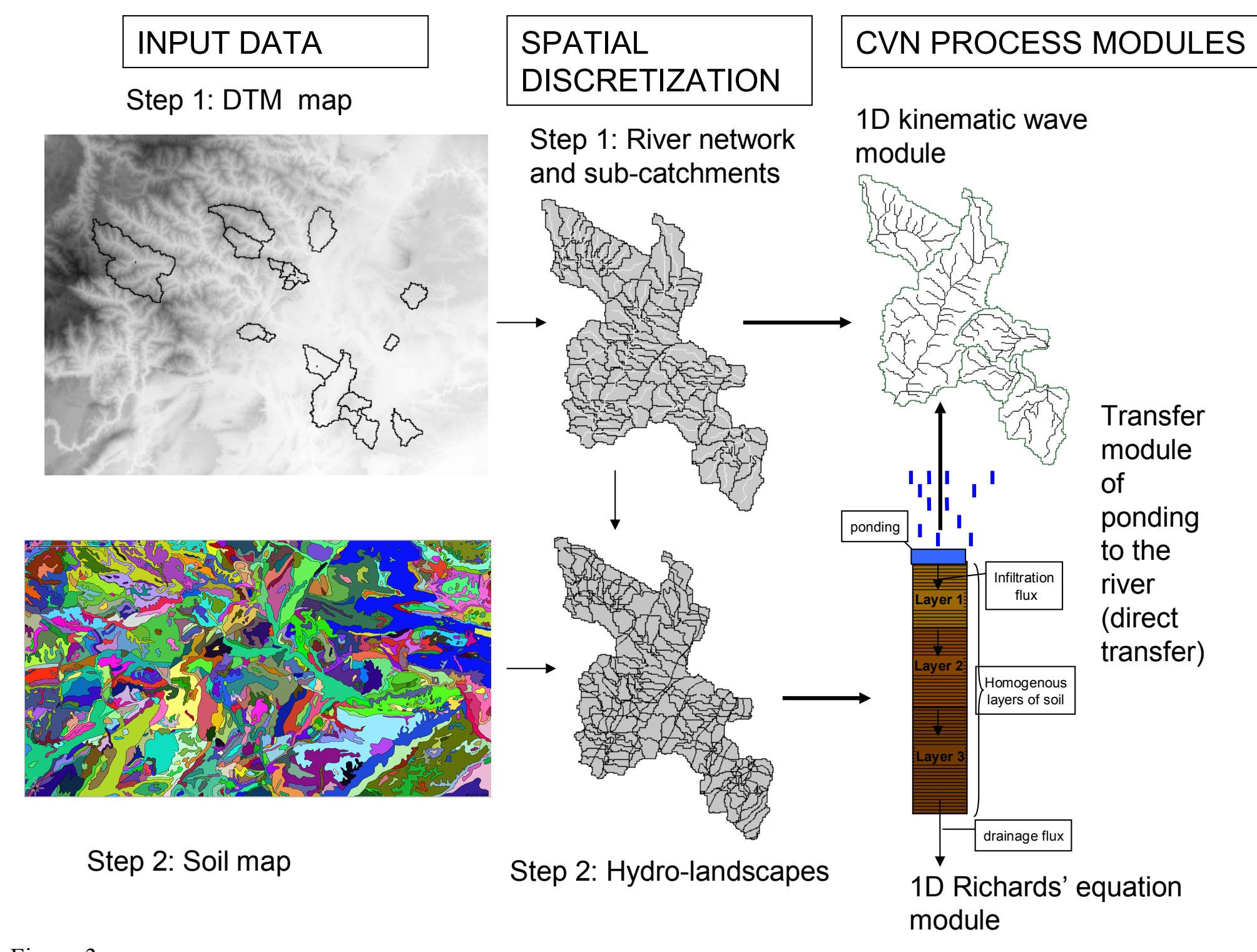

Figure 3 
a) Maximum storage capacity ( $\mathrm{mm})$
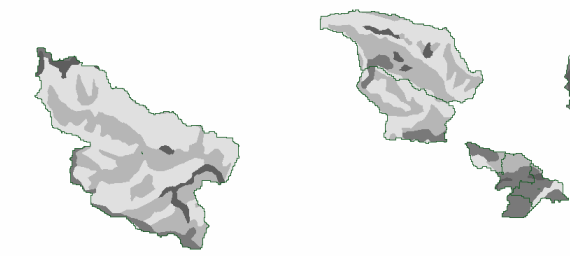

$0-50$

14. $50-100$

$100-200$

C200-400

$400-600$

c $600-820$

*

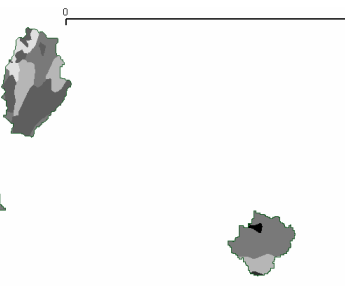

c) CVN initial deficit ( $\mathrm{mm}$ )
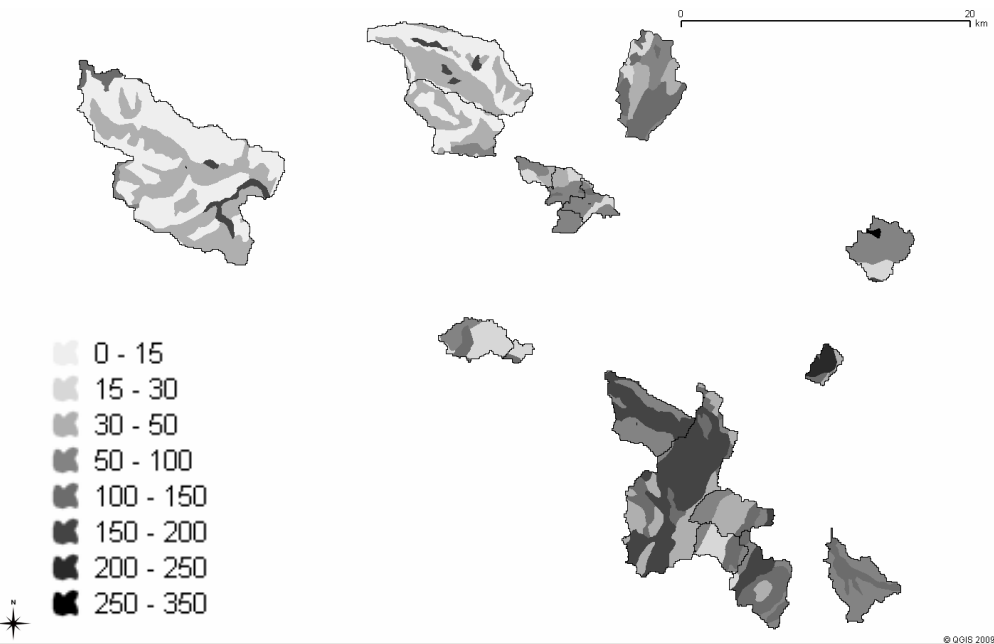

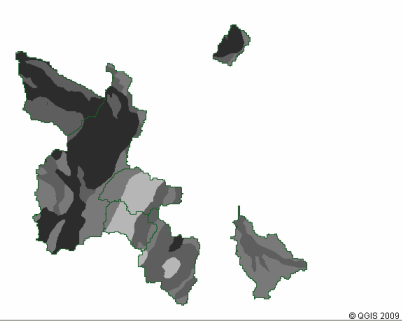

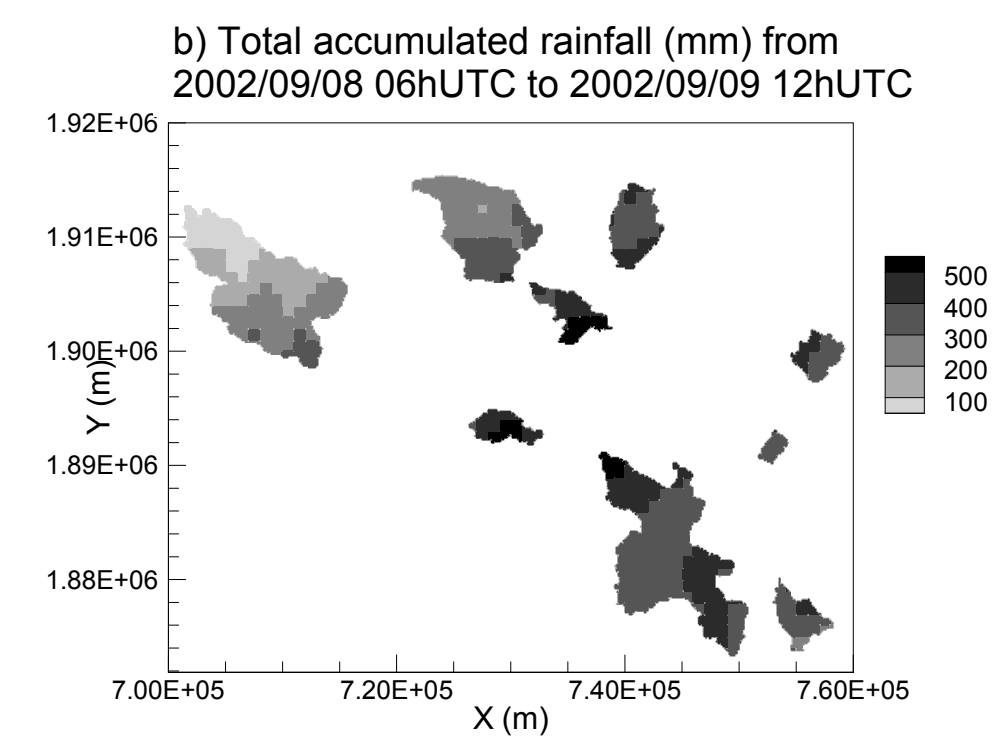

d) MARINE initial deficit (mm)
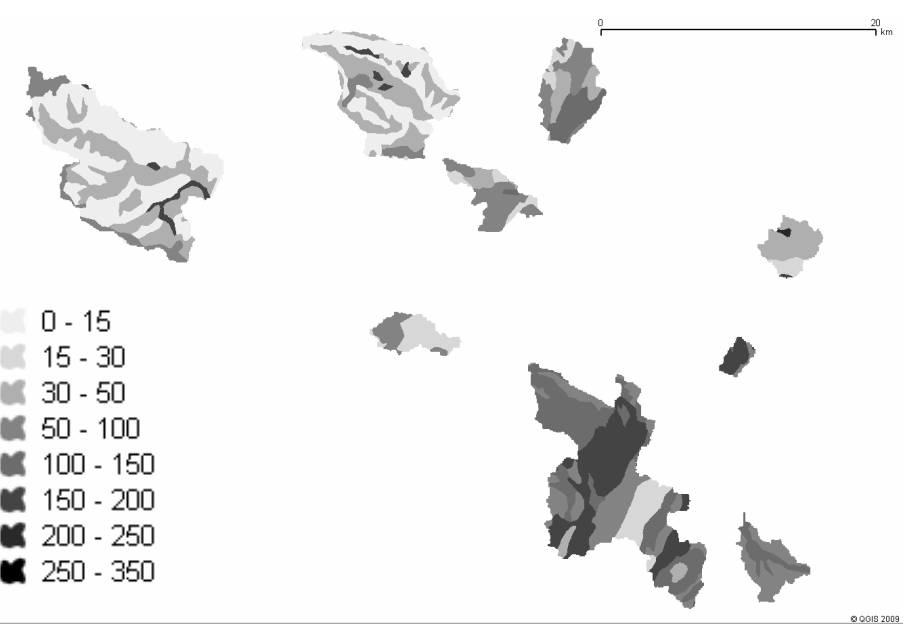

Figure 4 

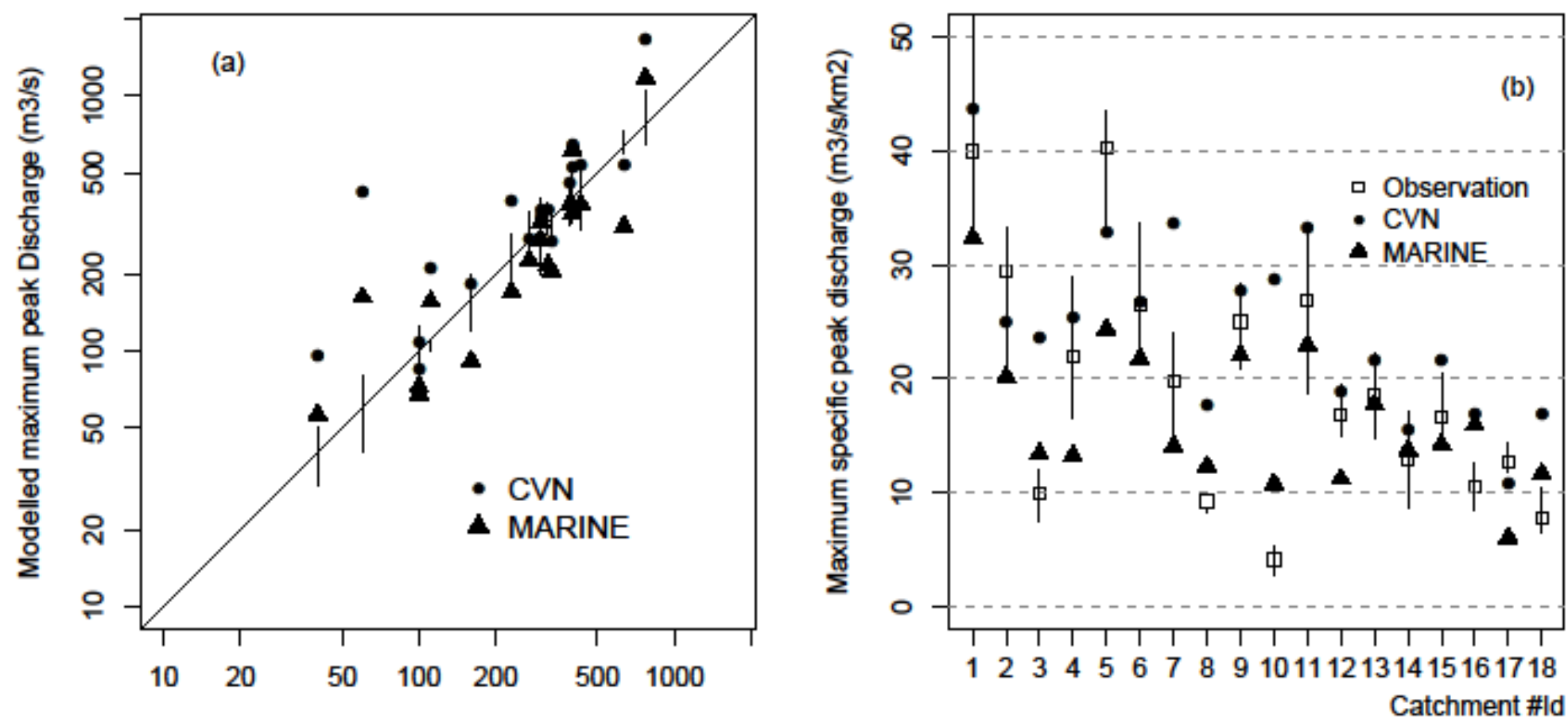

Figure 5 

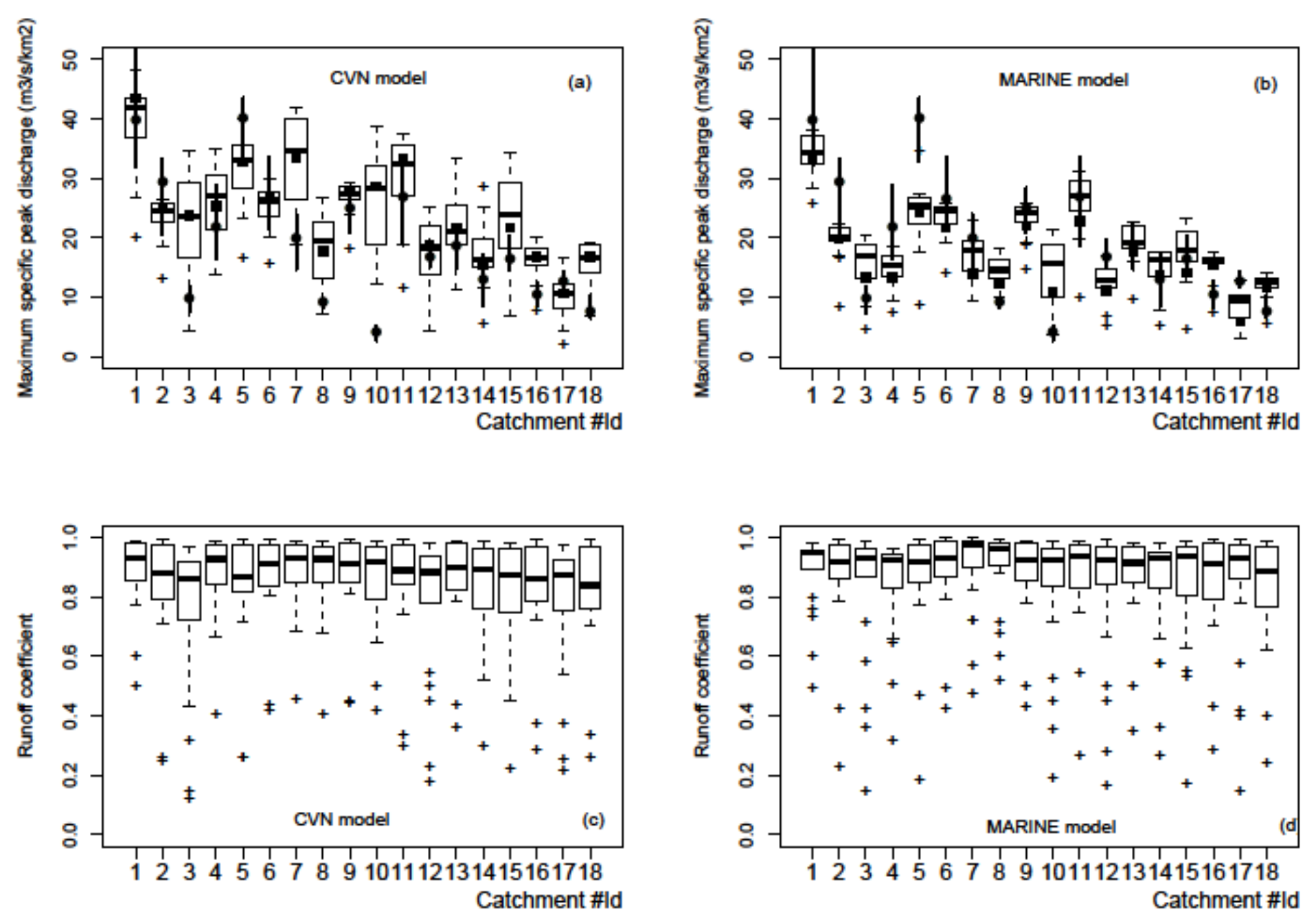

Figure 6 

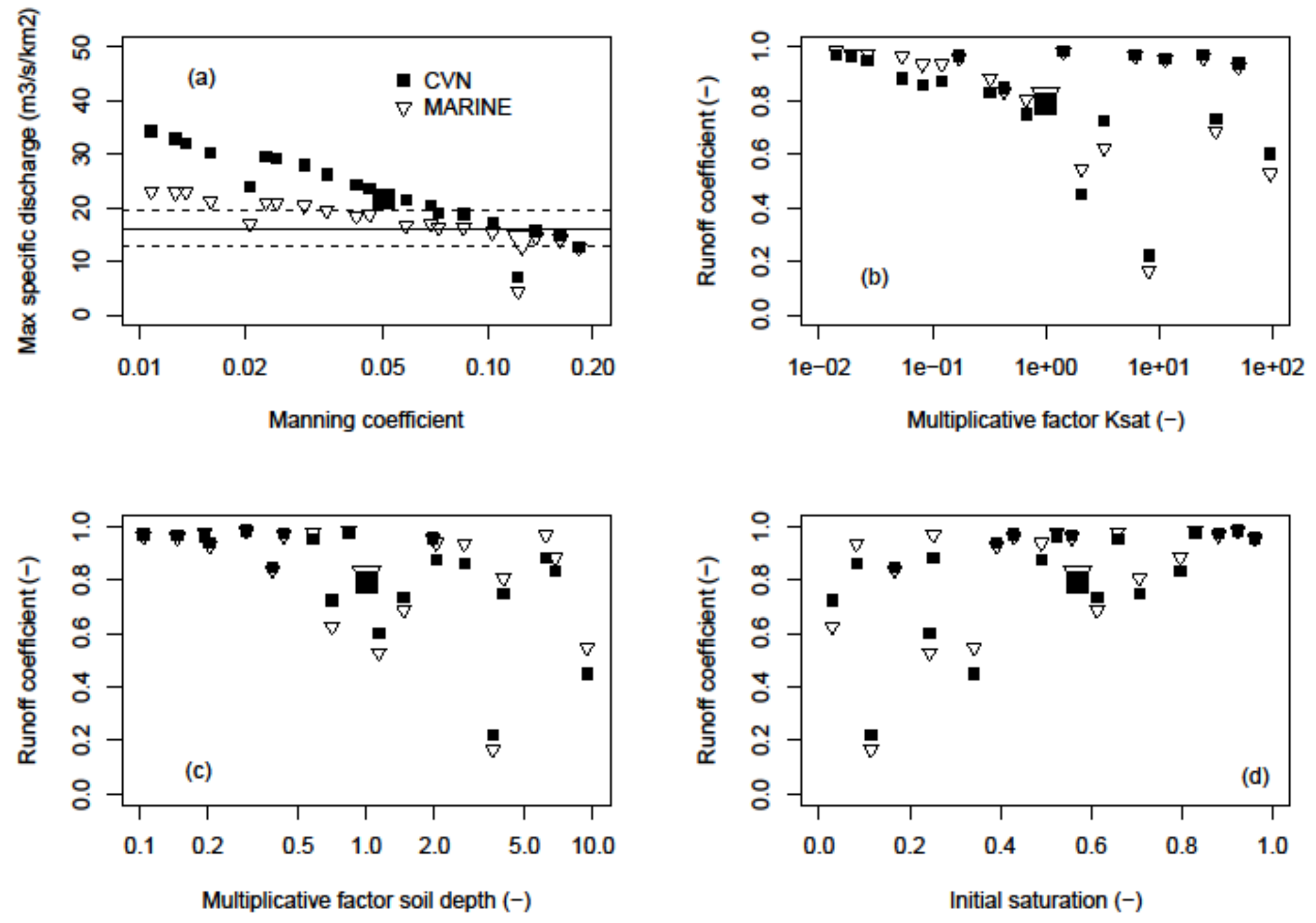

Figure 7 

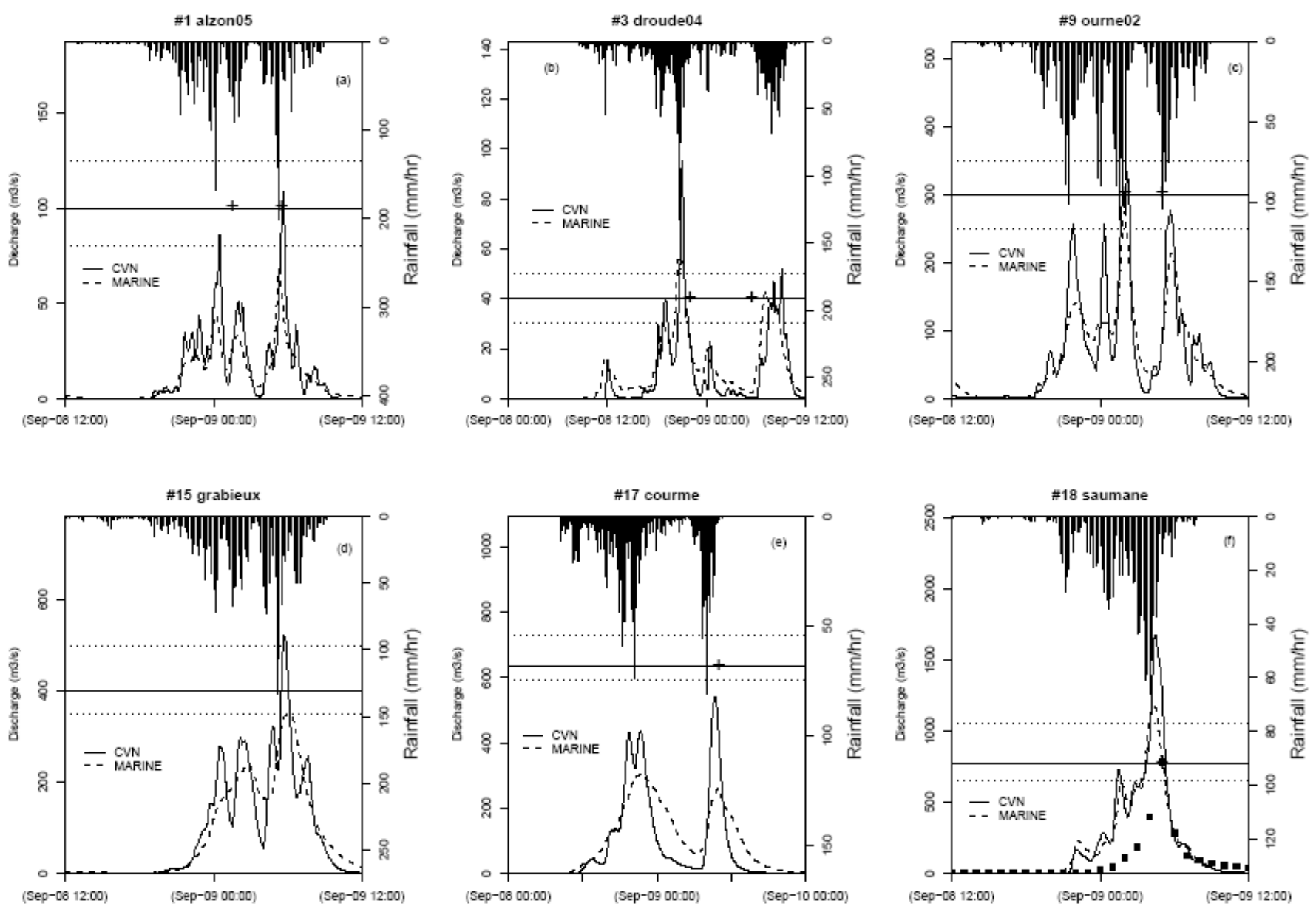

Figure 8 

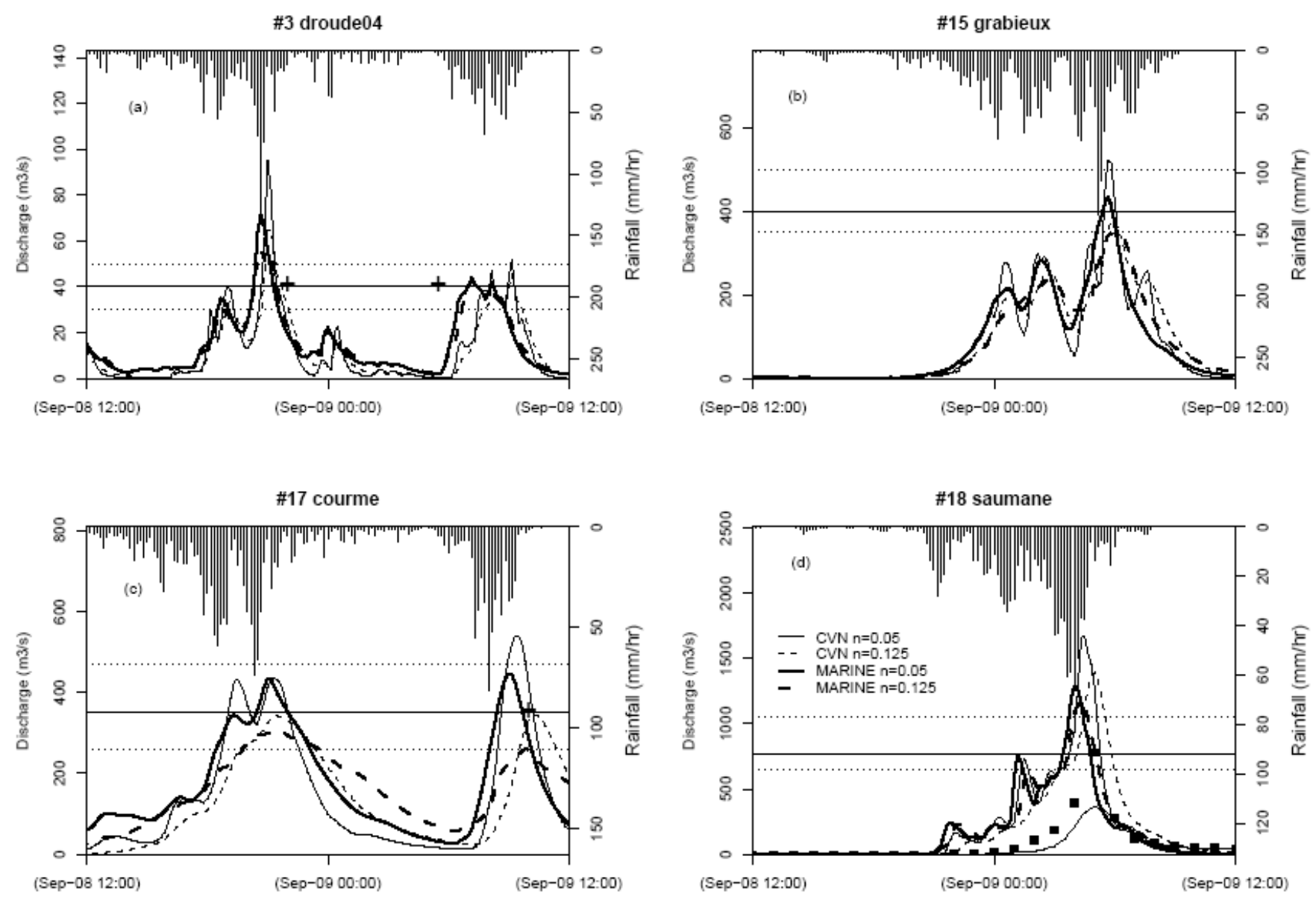

Figure 9 

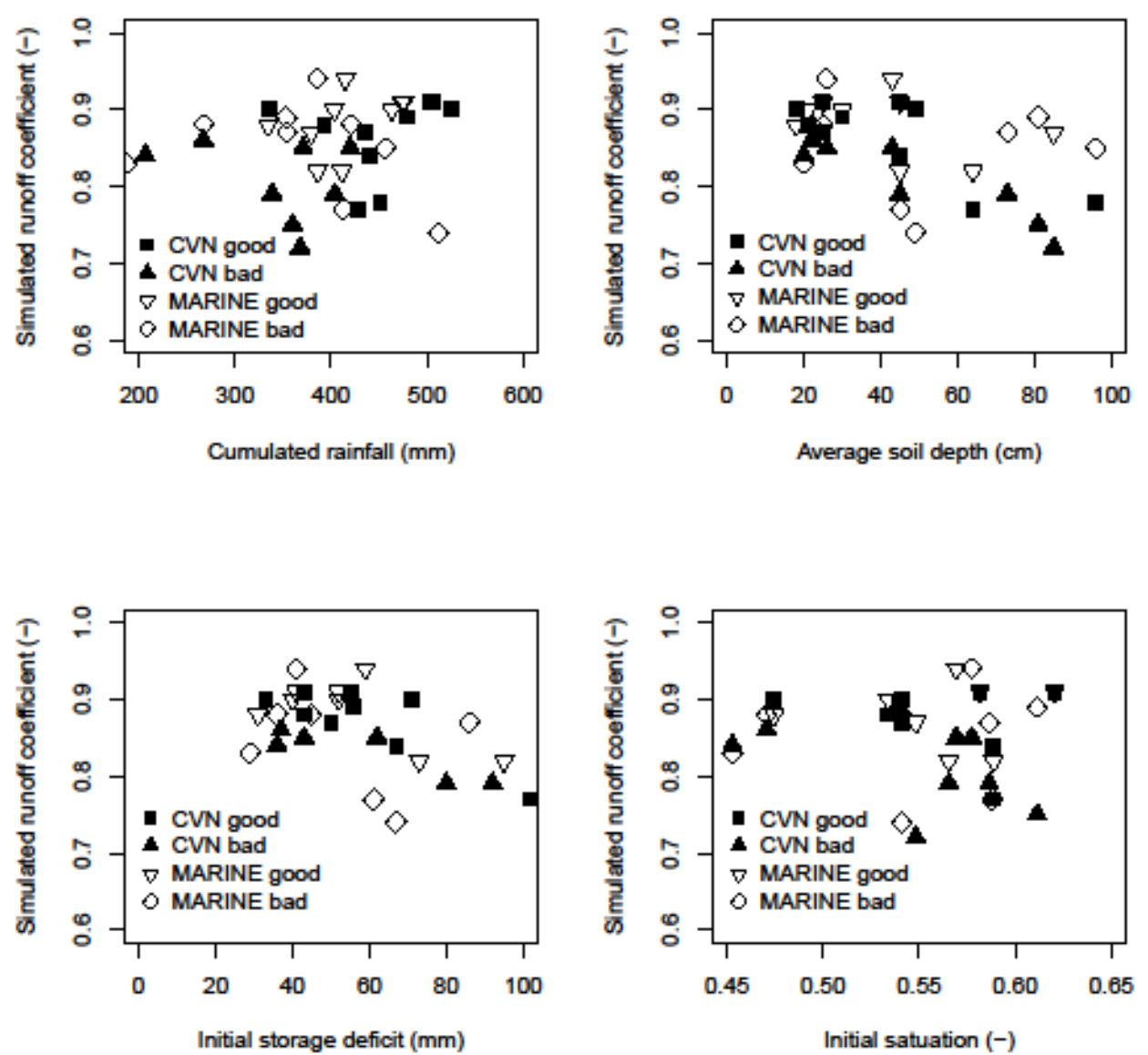

Figure 10 
Figure 10. Spatial distribution and time evolution of the saturation state of each catchment with a) CVN model b) MARINE model

$\mathrm{CVN}$

2002/09/08 12:00

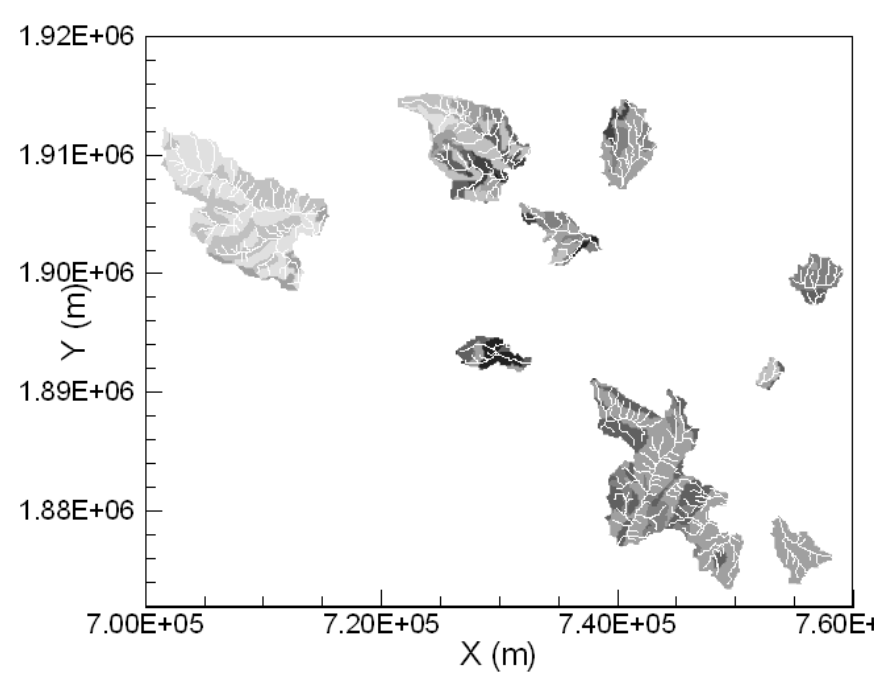

MARINE

2002/09/08 12:00

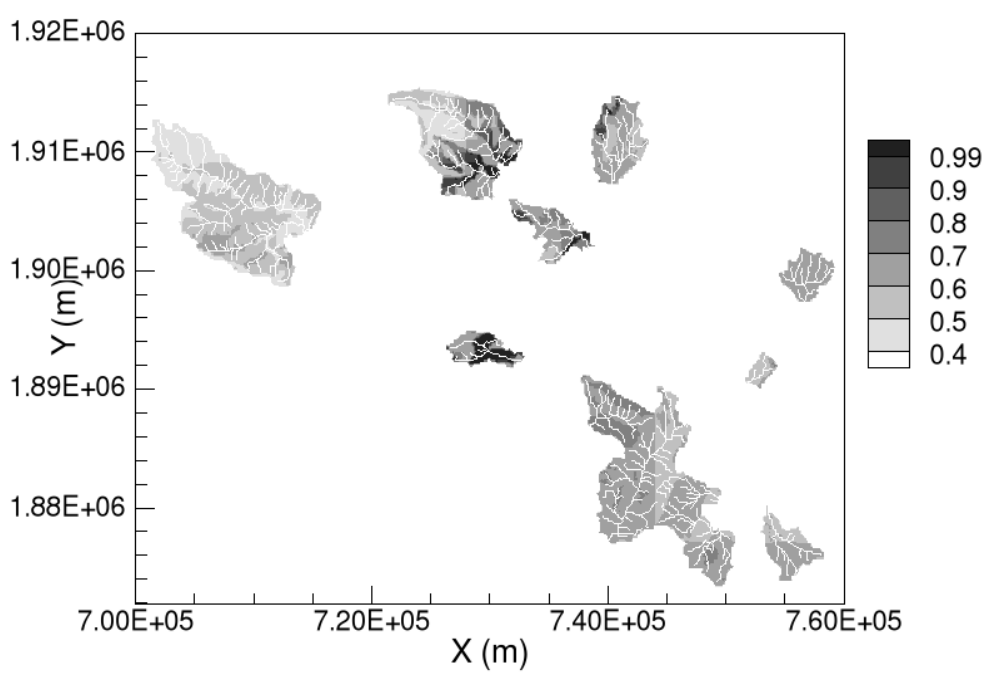

Figure 11 
$\mathrm{CVN}$

2002/09/09 00:00

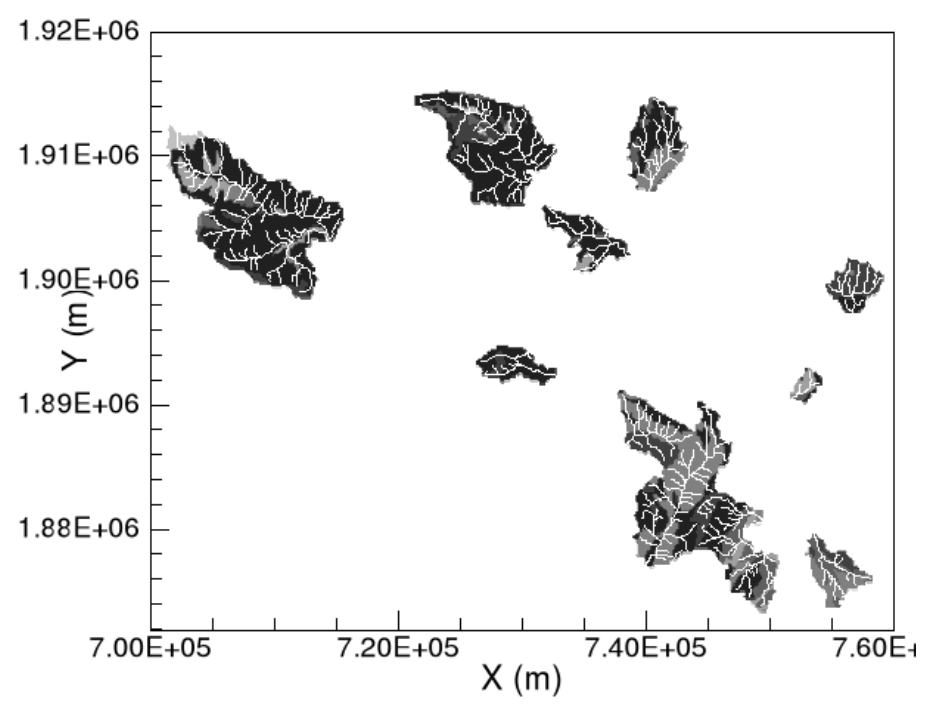

MARINE

2002/09/09 00:00

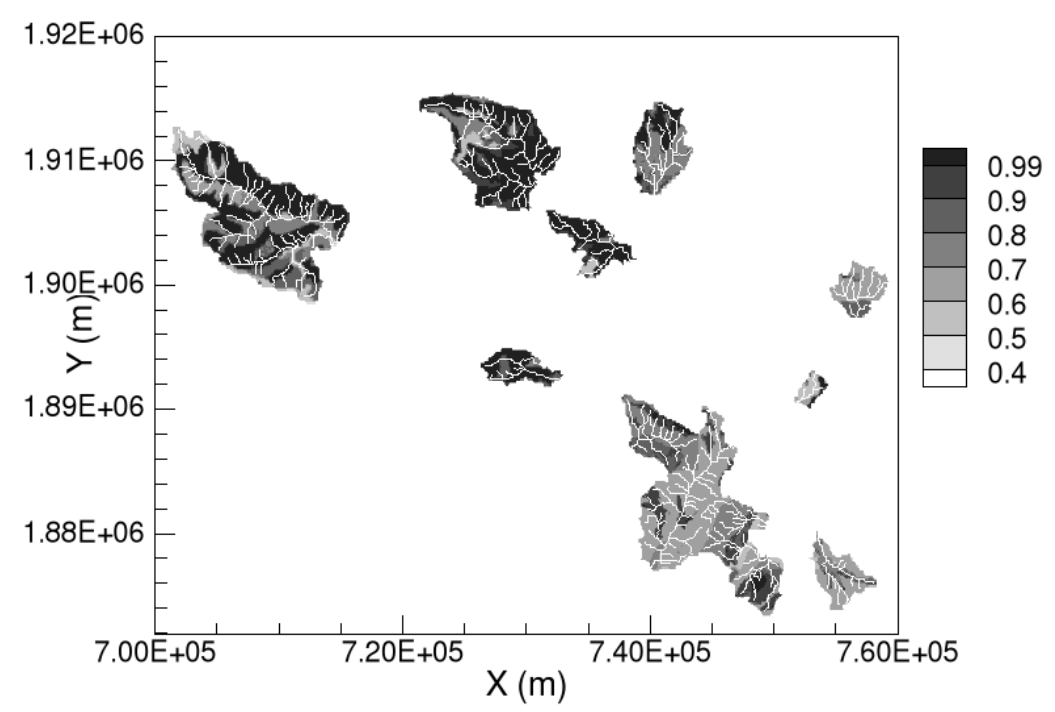

Figure 11 Continued 
CVN

2002/09/09 12:00

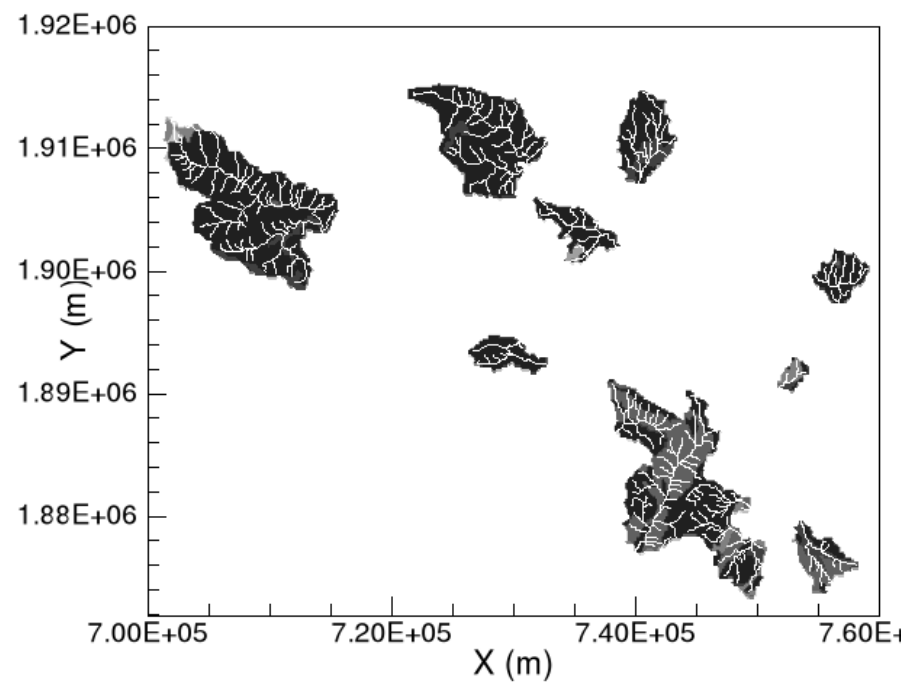

MARINE

2002/09/09 12:00

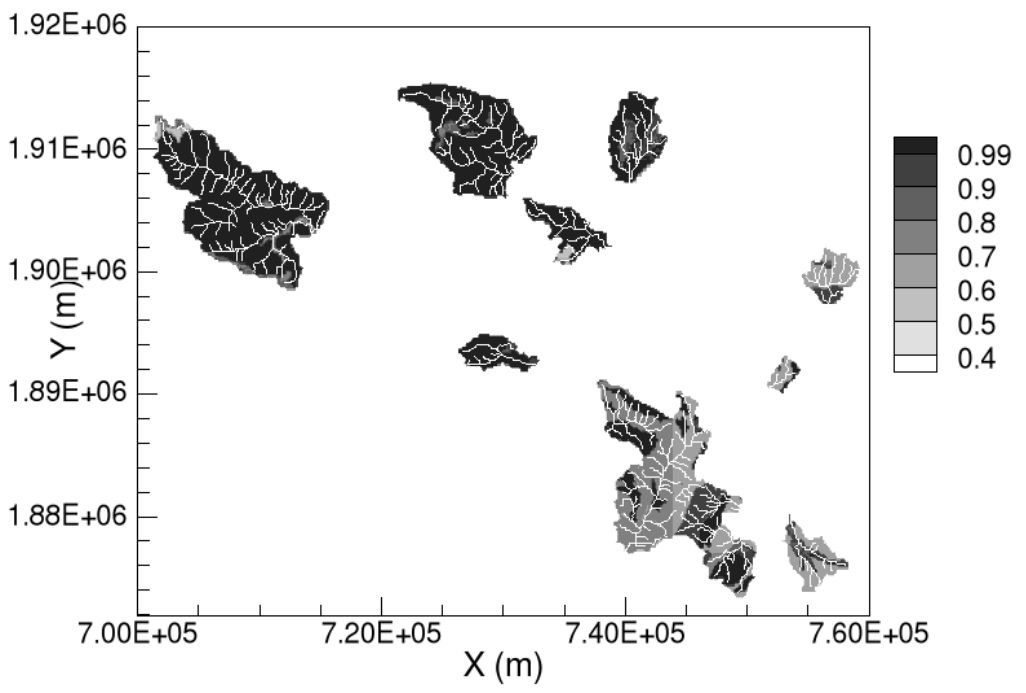

Figure 11 Continued 
Author-produced version of the article published in Journal of Hydrology, vol. 394, p. 162-181.

Figure 9. Time evolution of the mean saturation state of all the

studied area

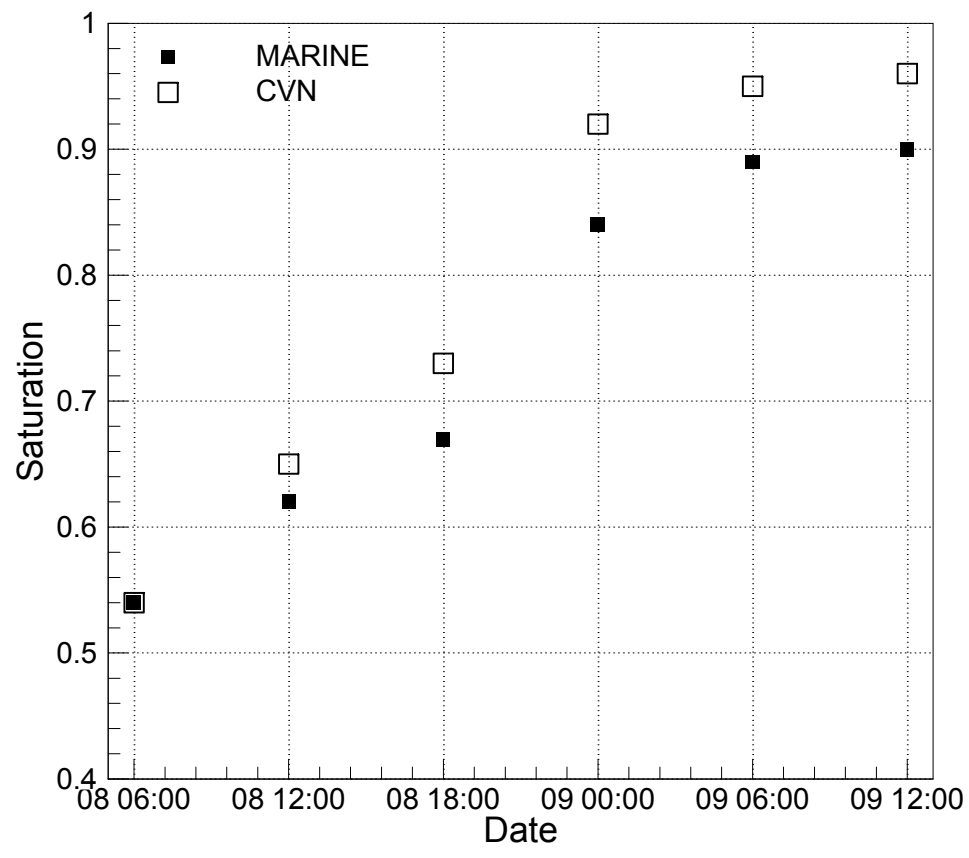

Figure 12 

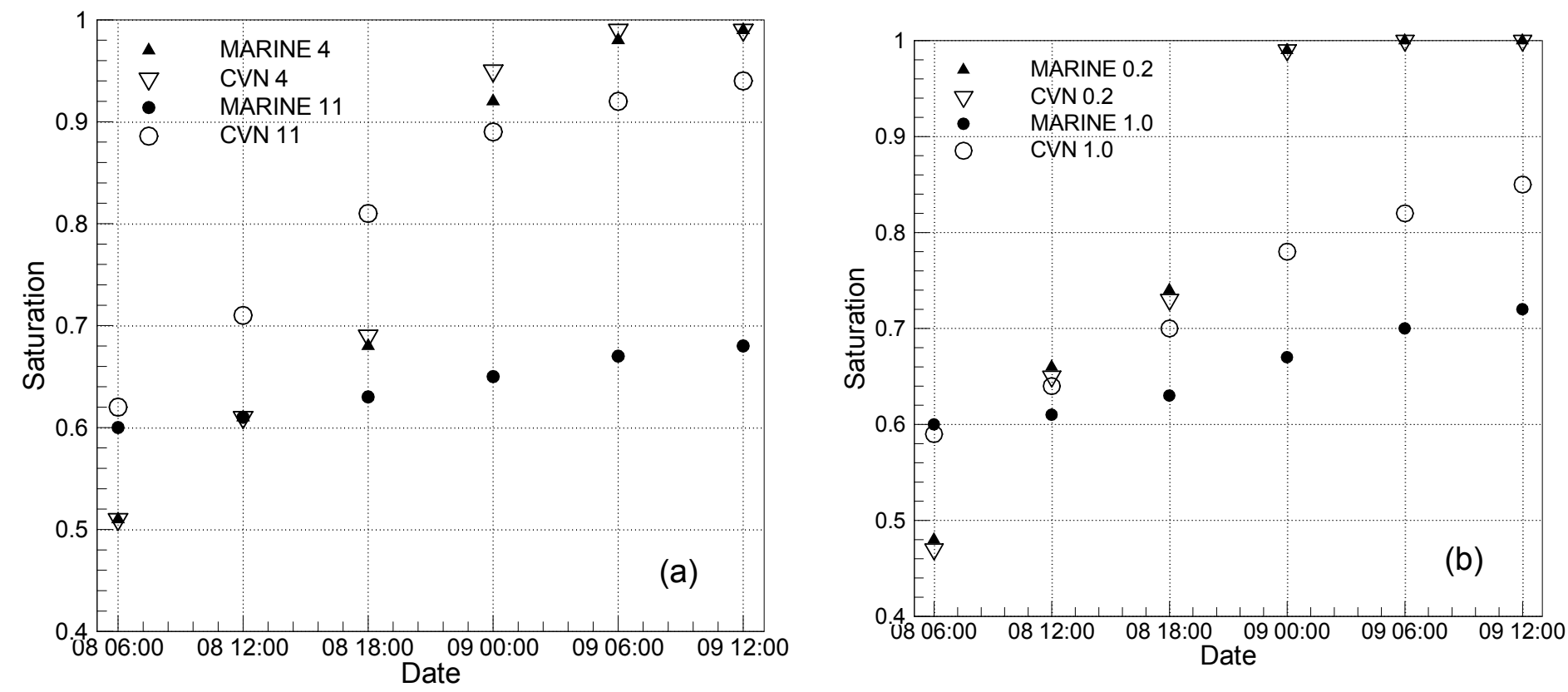

Figure 13 
Author-produced version of the article published in Journal of Hydrology, vol. 394, p. 162-181. The original publication is available at http://www.sciencedirect.com doi : 10.1016/j.jhydrol.2010.03.033
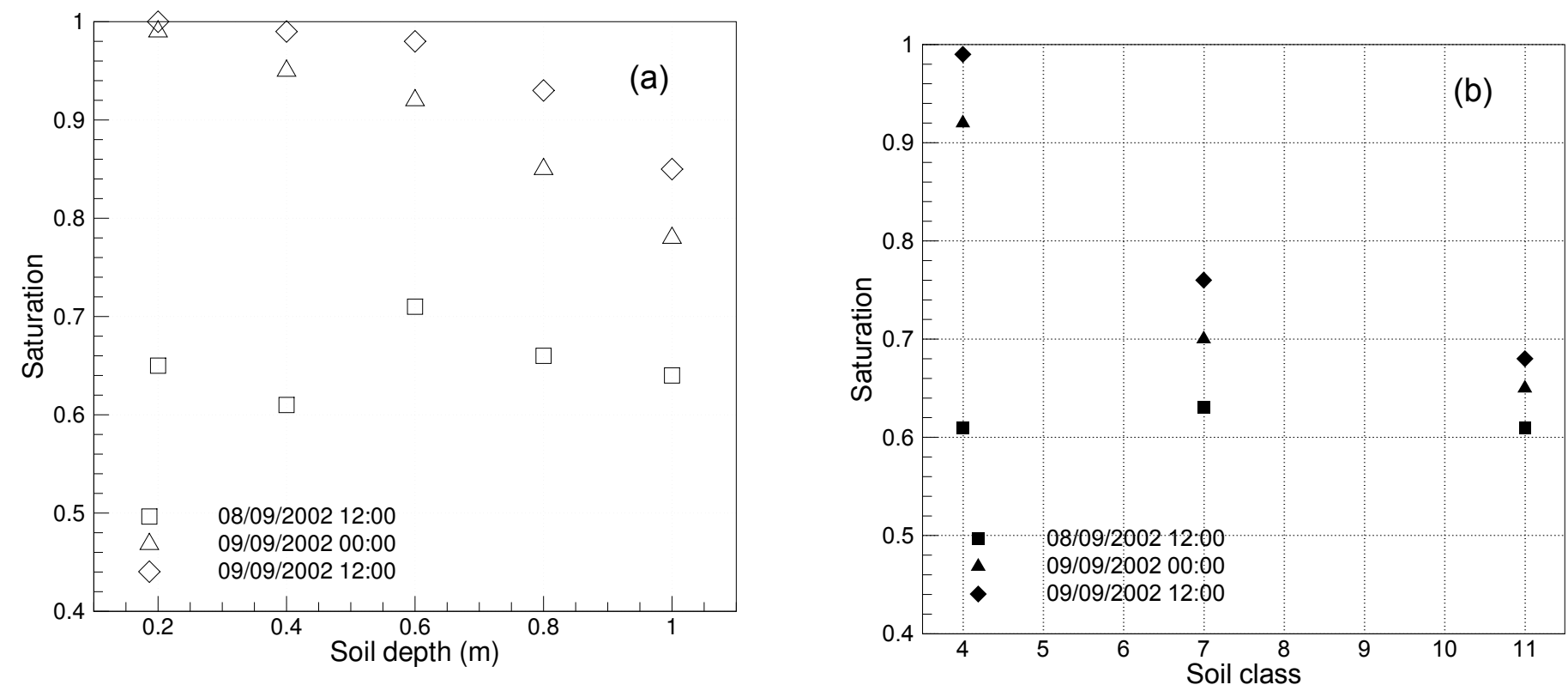

Figure 14 

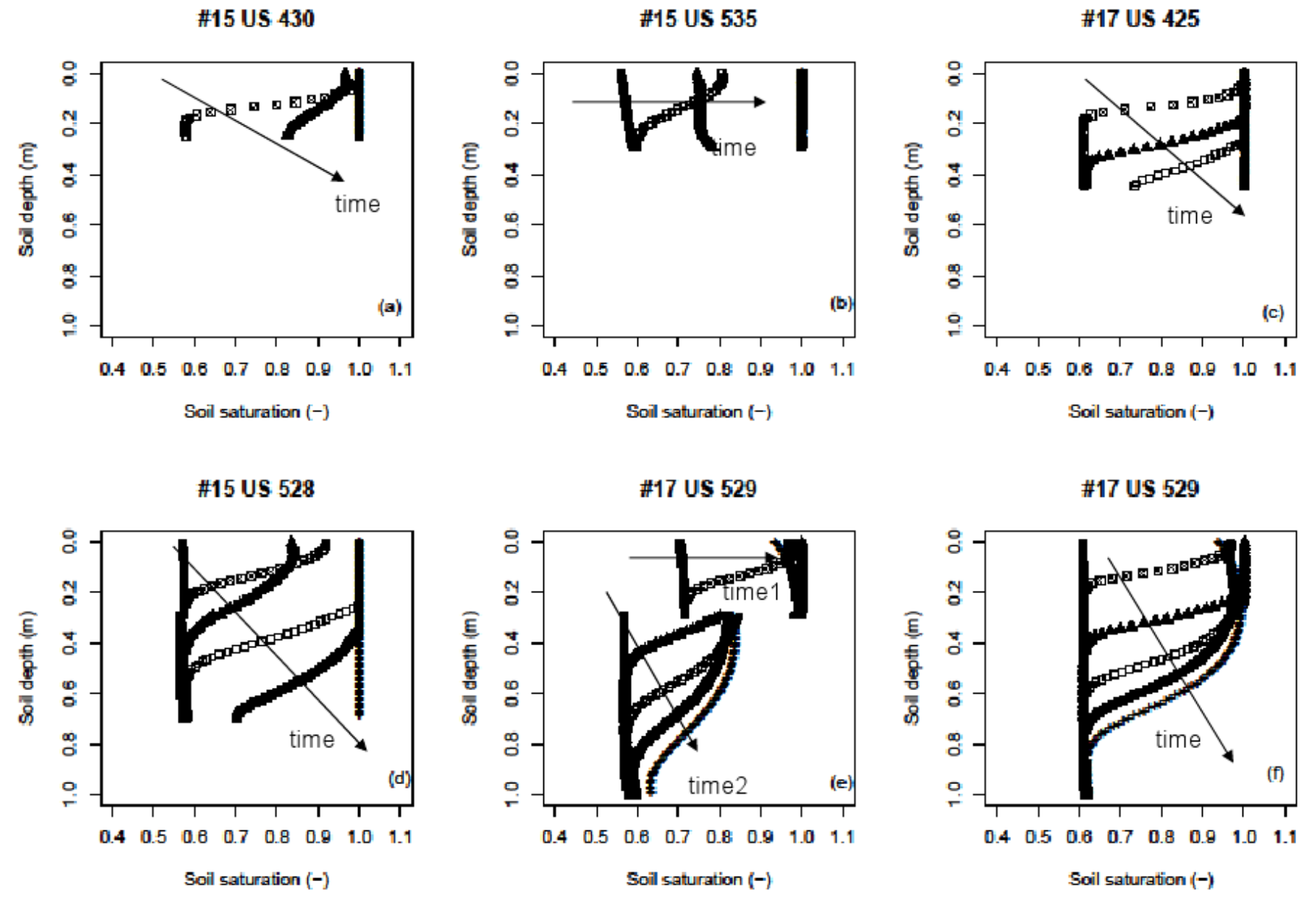

Figure 15 

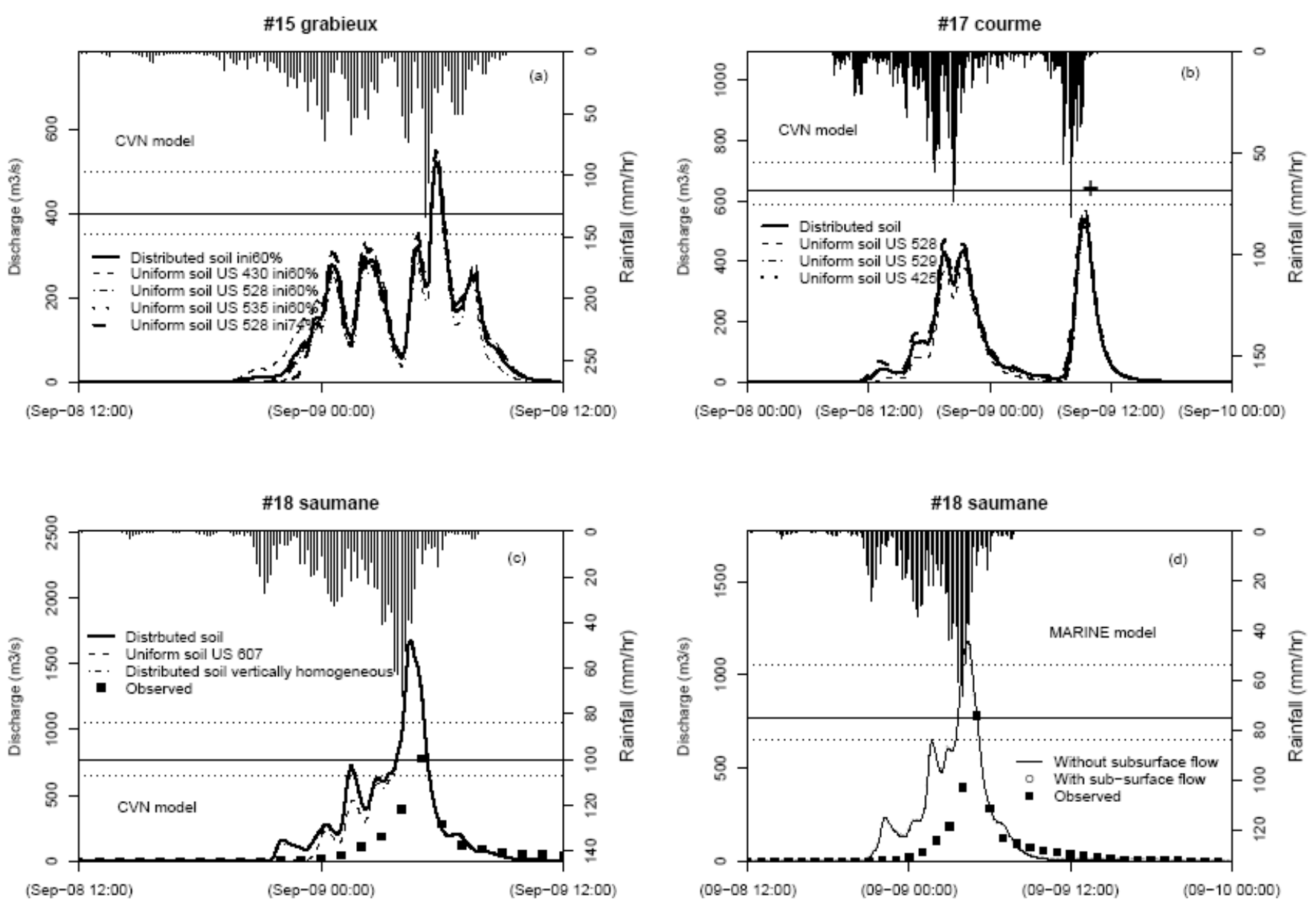

Figure 16 
(a)

MARINE

2002/09/09 12:00

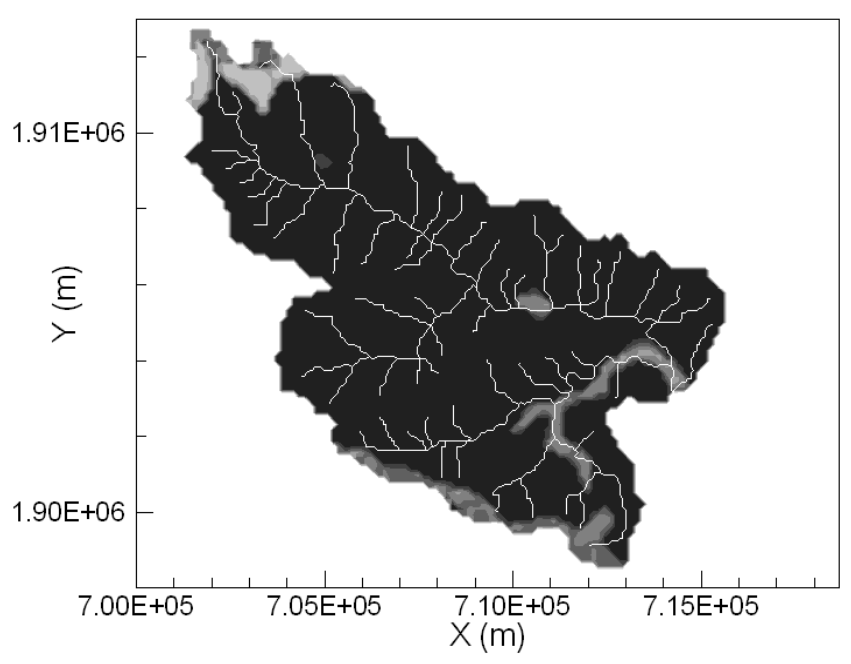

(b)

MARINE

2002/09/09 12:00

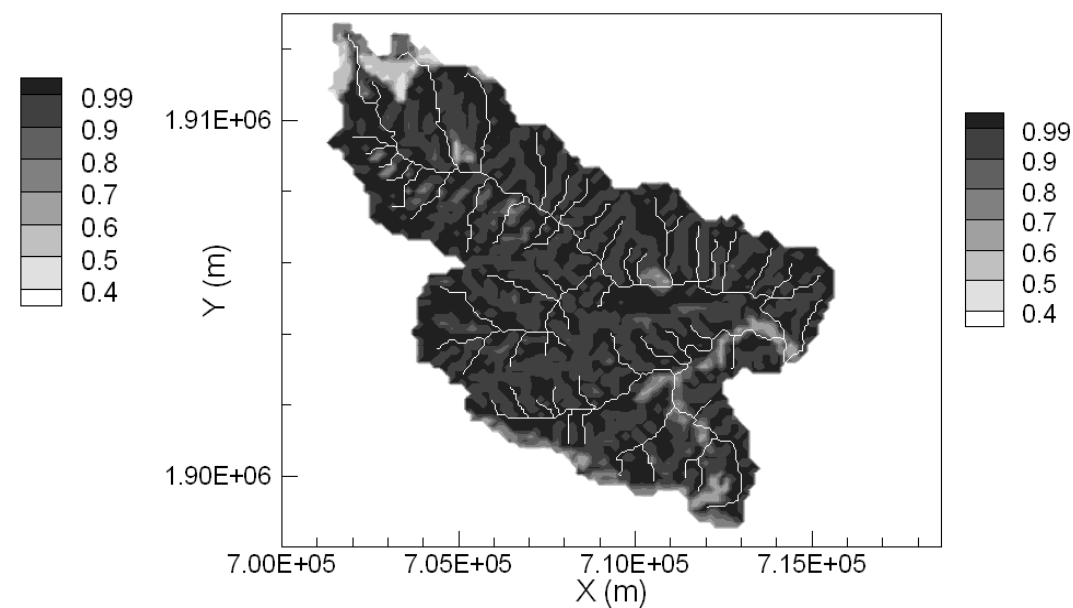

Figure 17 